\title{
V. Grundzüge einer liberalen Deutschlandpolitik in den Jahren nach dem Ersten Weltkrieg
}

\section{Der Eintritt in die große Politik: Liberale Programmatik am Rande des Bloc National}

\begin{abstract}
Als Mitglied des Rekrutenjahrgangs 1898 wurde Reynaud nach seiner Rückkehr aus den USA noch mit der ersten Demobilisierungswelle im April 1919 aus dem aktiven Dienst in der Armee entlassen und nahm ohne ersichtliche Schwierigkeiten seine Tätigkeit als Anwalt wieder auf. Sein Offiziersstatus, das familiäre Vermögen und ein weitgehend unversehrtes Netz persönlicher Verbindungen ersparten ihm das Schicksal vieler "poilus“, die aufgrund organisatorischer Probleme in den Demobilisierungsbehörden, einer verspäteten und ungünstigen Regelung des Entlassungsgeldes und selbst- oder fremdverschuldeter Schwierigkeiten bei der Rückkehr an den alten Arbeitsplatz oft in Enttäuschung, Verbitterung und Unzufriedenheit, nicht selten auch in materielle Not verfielen. ${ }^{1}$ Ohne zu zögern, knüpfte Reynaud an sein politisches Engagement der Vorkriegszeit wieder an, das er noch nicht einmal für die gesamte Dauer seines Militärdienstes unterbrochen hatte. So hatte er regelmäßig die Perioden seiner Heimaturlaube genutzt, um im Conseil Général seines Départements zu regionalen wie zu übergeordneten Fragen Lösungsvorschläge anzubieten, etwa im April 1917, als er vor wirtschaftlicher Nachkriegskonkurrenz für Frankreich durch seine ehemaligen Alliierten wie durch Deutschland warnte. ${ }^{2}$ Im August 1918, kurz vor seiner Abreise nach Sibirien, hatte er die Gelegenheit ergriffen, sich anläßlich eines Regierungsprojekts zur Erneuerung der Verwaltungseinteilung des Landes im Namen des Conseil Général der Basses-Alpes gegen die Einführung der „Region“ und statt dessen zugunsten einer grundlegenden Verfassungsreform auszusprechen. ${ }^{3}$ Für seine erneute Kandidatur um ein Abgeordnetenmandat wählte Reynaud im Herbst 1919 sein Heimatdépartement Basses-Alpes.
\end{abstract}

1 Die erste Welle der allgemeinen Demobilisierung, die nicht Einheit für Einheit vorgenommen wurde, sondern um der größeren Gerechtigkeit willen einen Einberufungsjahrgang nach dem anderen erfaßte, betraf die Klassen 1887 bis 1906, die zwischen Dezember 1918 und April 1919 entlassen wurden. Dazu und zur Lage der Entlassenen vgl. Prost, Anciens combattants I, S. 47-53. Wichtige Ergebnisse seiner Studie sind in kondensierter Form enthalten in: Ders., Die Demobilmachung, der Staat und die Kriegsteilnehmer in Frankreich, in: Geschichte und Gesellschaft 9 (1983), S. 178194.

2 Vgl. den Bericht dazu in: Journal de Barcelonnette, 3. 11. 1919.

3 Der Text seines Berichts vom 28. 8. 1918 findet sich in: Conseil Général du département des BassesAlpes. Rapports du Préfet et procès-verbaux des délibérations, 2e session ordinaire 1918 (Archives Départementales des Alpes-de-Haute-Provence, $1 \mathrm{~N}$ 44). Er ist auch wiedergegeben in: Journal de Barcelonnette, 22./23./24. 9. 1918. Vgl. Reynaud, Mémoires I, S. 104-108. 
Die Parlamentswahlen vom November 1919 beendeten einen „Schwebezustand zwischen Krieg und Frieden" ${ }^{4}$, der das politische Leben Frankreichs noch knapp ein Jahr nach Abschluß des Waffenstillstands mit Deutschland gekennzeichnet hatte. In mehrfacher Hinsicht hatten bis dahin auch auf politischem Gebiet die Übergangsregelungen der Kriegszeit fortgedauert. So war nicht nur die Regierung Clemenceau unverändert im Amt geblieben, auch die seit den Wahlen vom Mai 1914 tätige Chambre des Députés hatte ihr im Frühjahr 1918 erschöpftes Mandat zunächst fortgeführt. Für die anstehenden Neuwahlen, die neben der Kammer der Abgeordneten, den Gemeinde- und Départementsräten auch einen Teil des Senats betrafen, setzte Clemenceau im Oktober einen Zeitplan durch, der die Kammerwahlen als ersten einer bis Januar 1920 dauernden Folge von Wahlgängen vorsah. ${ }^{5}$

Das Département Basses-Alpes war in ganz besonderer Weise von der Strukturkrise betroffen, die die Gesamtheit der ärmeren alpinen Regionen Frankreichs seit Beginn des 19. Jahrhunderts heimsuchte und die in einer teilweise dramatischen Abwanderung der Bevölkerung ihren Ausdruck fand. Zwischen 1806 und der Mitte des 20. Jahrhunderts verlor es $35 \%$ seiner Einwohner, wobei ein besonders starker Rückgang während des Jahrzehnts zwischen 1911 und 1921 - nicht zuletzt bedingt durch die Folgen des Krieges - zu verzeichnen war. ${ }^{6}$ Das stark landwirtschaftlich geprägte Département, dessen Bevölkerungszahl in der unmittelbaren Nachkriegszeit unter 100000 Einwohnern lag, hatte im Herbst 1919 mit sozialen und wirtschaftlichen Schwierigkeiten zu kämpfen, die im wesentlichen aus national wirksamen wie regional begründeten Problemen bei der Beseitigung der Kriegsfolgen und der Umstellung auf die Friedenswirtschaft resultierten. Die Industrieproduktion des Départements war auf drei während des Krieges errichtete Fabriken zur Herstellung chemischer Ausgangsprodukte für Sprengstoffe und Kampfgas konzentriert geblieben und nach Kriegsende weitgehend zum Erliegen gekommen. Die rasch in Angriff genommene Umrüstung der Betriebe auf die Produktion von Elektrizität aus Wasserkraft bzw. auf am Friedensbedarf orientierte Chemieprodukte hatte zu Entlassungen und einschneidenden Gehaltskürzungen bei den verbliebenen Arbeitern geführt. Neuen Elan hatte die landwirtschaftliche Tätigkeit in der Region mit der Rückkehr der demobilisierten Landwirte erhalten: Man zeigte sich offen für Innovationen, und neubelebte genossenschaftliche Vertretungen entfalteten intensive Aktivitäten zur Einführung der Motorkraft in den Ackerbau. Grundsätzlichere Mängel wie das Fehlen von chemischem Dünger gefährdeten jedoch auch künftig die Ernten. Die Auswirkungen der Inflation waren im Département in Form einer allgemeinen starken Steigerung der Lebenshaltungskosten spürbar geworden, was nicht zuletzt zu einer Überlastung der staatlichen Fürsorgestellen und zur Verdoppelung der Zahl von Kindesaussetzungen innerhalb weniger Monate seit Jahresmitte 1919 geführt hatte. Die aufgrund der Wirtschaftslage prekäre Finanzsituation des Départe-

${ }_{4}$ René Rémond, Frankreich im 20. Jahrhundert. Erster Teil 1918-1958 (Geschichte Frankreichs 6), Stuttgart 1994, S. 59.

5 Ebenda, S. 59 f.; Mayeur, Troisième République, S. 251-254.

- Christiane Vidal, Chronologie et rythmes du dépeuplement dans le département des Alpes de Haute-Provence depuis le début du XIXe siècle, in: Provence Historique 21 (1971), S. 281-291. Bislang existiert keine wissenschaftliche Geschichte des Départements. 
ments wiederum hatte trotz deutlicher Erhöhung der Gemeindeabgaben die Verschiebung dringender Ausgaben um ein halbes Jahr nötig gemacht, die Beschäftigten der Départementsverwaltung konnten bis auf weiteres nur durch Vorschüsse auf ihr Einkommen bezahlt werden. ${ }^{7}$

Vor diesem regionalen Hintergrund gingen die Wahlen erstmals nach dem neuen modifizierten Verhältniswahlrecht vor sich, welches das seit 1889 gültige Mehrheitswahlrecht mit Wirkung vom 12. Juli 1919 abgelöst hatte. Es stellte einen Kompromiß dar, der die stagnierende Frage der Wahlrechtsreform wieder in Fluß gebracht hatte, nachdem ein stark durch den Proporzgedanken geprägter Kammerentwurf vom Juli 1912 noch im Jahr 1913 am Veto der Verhältniswahlgegner im Senat gescheitert war. ${ }^{8}$ Das neue Wahlgesetz erweiterte die Wahlkreise von der Ebene des Arrondissements auf diejenige des Départements und sah die Abstimmung nach Listen vor, an die die Sitze entsprechend der erreichten Stimmenzahl auf der Basis eines komplexen Schlüssels vergeben werden sollten. Das Mehrheitsprinzip lebte darin in revidierter Form fort: Einen besonderen Bonus erhielten jene Listen, worin mindestens ein Mitglied die absolute Mehrheit der Stimmen erreicht hatte. Sie bekamen diese Mandate zusätzlich zu ihren nach der Verhältnisklausel ermittelten Sitzen zugewiesen. ${ }^{9}$

Bis zum Wahltermin hatten sich im Département sechs Listen gebildet. Zusammen mit seinen vier Mitbewerbern der „Liste d'Union et de Concentration Républicaine" - darunter neben André Honnorat zwei weitere ehemalige Abgeordnete - stellte sich Reynaud während einer Rundreise durch die Orte des Wahlkreises vor und präsentierte das gemeinsame Programm. Es wies wie alle übrigen Entwürfe der bürgerlichen Gruppen, einschließlich derjenigen der sozialistischen Partei und des radikalsozialistischen Kandidaten eine starke Komponente zugunsten der Demobilisierten auf: Einhellig sprach man sich für die verbesserte finanzielle Unterstützung der „ancien combattants“ aus und favorisierte die strikte Besteuerung überhöhter Kriegsgewinne wie die Reduzierung des Wehrdienstes auf ein Jahr im Rahmen allgemeiner Abrüstung in Europa. ${ }^{10}$ Daneben bot man unter allen Bewerbern den detailliertesten Katalog konkreter Maßnahmen. Unter dem allgemeinen Vorzeichen antibolschewistischen Engagements, das besonders durch

7 Préfecture des Basses-Alpes. Cabinet du Préfet. Rapport Mensuel. Mois de Septembre 1919, 29.9. 1919 (AN, F713030). Bedauerlicherweise sind die im Pariser Nationalarchiv aufbewahrten Präfektenberichte für das Département Basses-Alpes äußerst lückenhaft, fehlen für die zwanziger Jahre fast völlig und sind erst ab Beginn der dreißiger Jahre in größerer Dichte vorhanden.

8 Zur Geschichte der Einführung der Verhältniswahl nach dem Ersten Weltkrieg und zu den vorausgegangenen langwierigen Diskussionen: Scherer, Verhältniswahl, S. 632-708.

9 Zum Wahlmodus im einzelnen: Georges Lachapelle, Elections législatives du 16 novembre 1919. Résultats officiels, Paris 1920. Mangels offizieller Statistiken gab Lachapelle die Zahlen anhand der "Procès-verbaux des commissions de recensement général des votes" wieder und analysierte sie. Irrtümlich spricht er allerdings bei der Beschreibung des Wahlmodus davon, daß eine Liste mit einem durch absolute Mehrheit gewählten Kandidaten alle zu vergebenden Sitze erhielte (S. $15 \mathrm{f}$.). Dies geht aus dem Wahlgesetz jedoch nicht hervor (Das Gesetz vom 12.7.1919 findet sich abgedruckt bei Scherer, Verhältniswahl, S. 737-740).

10 Die Wahlergebnisse und die "professions de foi" aller sechs Listen des Départements finden sich abgedruckt in: Chambre des Députés. Douzième Législature. Session de 1920. Annexe au procèsverbal de la séance du 28 juillet 1920. Programmes, Professions de foi et engagements électoraux de 1919, Paris 1920, in: Chambre des Députés. Douzième Législature. Impressions. Projets de lois, propositions, rapports, etc. Tome XIX, No. 1431 (Programmes électoraux), Paris 1924, S. 1-1028, hier: S. 30-43. 
Reynaud in seiner ersten öffentlichen Rede im Département betont wurde, rückte man die Notwendigkeit sozialer, finanztechnischer und allgemein politischer Reformen zur Stabilisierung des Landes in den Mittelpunkt. Maßnahmen wie die Erhöhung der Einkommensteuer auf große Verdienste, die Einführung einer Kapitalsteuer mit Erleichterungen für Investoren und große Familien sollten die Konsolidierung des Staatshaushalts und die Regelung der Kriegsschulden ermöglichen, die Einführung der Zwangsschlichtung bei Arbeitskämpfen, die Kompetenzenerweiterung der Gewerkschaften und der erleichterte Zugang der Arbeiter zum Besitz den sozialen Frieden garantieren. Von der Bildung schließlich einer großen, mehrheitsfähigen republikanischen Partei, von parlamentarischen Reformen wie der obligatorischen Trennung des Abgeordnetenmandats vom Ministeramt oder der Einführung einer „Présidence du Conseil“ erwartete man die Behebung des Übels instabiler Regierungen und unzuverlässiger parlamentarischer Mehrheiten. ${ }^{11} \mathrm{Als}$ einzige aller im Département angetretenen Listen bekannte man sich als dem "Bloc national républicain" nahestehend.12

Dieses auf nationaler Ebene im Oktober 1919 aus der Taufe gehobene Wahlbündnis entsprach weder vor noch nach dem Wahlgang vom 16 . November jenem geschlossenen „Block“, den die Namensgebung suggerierte. Nicht zuletzt mit Blick auf das neue Wahlrecht, das die Bildung möglichst großer, einheitlicher Listen nahelegte, sollten alle Fraktionen des einen „parti républicain" unter dem programmatischen Vorzeichen einer über das Kriegsende hinaus fortzuführenden „union sacrée" vereint werden. Das Gründungsmanifest vom 22. Oktober 1919 umfaßte denn auch neben der klassischen Rechten in der "Fédération Républicaine" die "Alliance Républicaine Démocratique“, den „Parti républicain radical et radical socialiste“, den „Parti Républicain Socialiste“ und die Interessenvertretung „Comité Républicain du Commerce, de l'Industrie et de l'Agriculture“ des Senators Mascuraud. Strikte Bindekraft gewann das Wahlbündnis allerdings nicht, und angesichts der lockeren Strukturen der beteiligten Gruppierungen war dies auch kaum zu erwarten. Durch deren Pariser Führungskader konzipiert und abgeschlossen, konkretisierte sich das Bündnis vor Ort schon im Vorfeld der Wahlen in einer proteushaften Vielfalt von Listenkombinationen. Sie verliehen ihm entgegen seinem übergreifenderen Anspruch de facto im Lande den Charakter einer losen Allianz der Rechten mit der rechten Mitte unter Einschluß nationalistischer Gruppen und der katholischen „Action Libérale Populaire“. Trotz des offiziellen Austritts des Exekutivkomitees der Radikalsozialisten aus dem „Bloc“ am 7. November figurierten nicht selten Mitglieder dieser Partei weiterhin auf den Listen des Bündnisses; vereinzelt wurden sogar Listen unter Beteiligung der monarchistischen „Action française“ gebildet. ${ }^{13}$ Entsprechend der heterogenen Zusammen-

1 Ebenda, S. 31-33; Journal de Barcelonnette, 3. 11. 1919. Ein Bericht über eine Wahlveranstaltung der Liste Reynauds findet sich unter dem Titel: „La liste d'Union et de concentration républicaine à Barcelonnette", ebenda, 12.11. 1919.

12 So in der gemeinsamen "profession de foi" der Liste: Chambre des Députés. Douzième Législature. Session de 1920. Annexe au procès-verbal de la séance du 28 juillet 1920. Programmes, Professions de foi et engagements électoraux de 1919, in: Impressions. Tome XIX, S. 33. Auch berief man sich auf die den "Bloc national“ unter anderem begründende Rede Clemenceaus in Strasbourg vom 3. 11. 1919: Journal de Barcelonnette, 12.11.1919.

13 Der "Appell du 22 octobre 1919“ findet sich abgedruckt in: Chambre des Députés. Douzième 
setzung des Blocks nahm man zudem bewußt davon Abstand, die beteiligten Gruppen auf ein allzu präzises gemeinsames Programm zu verpflichten. ${ }^{14}$ Allerdings kristallisierte sich ein Kernbestand von Punkten heraus. Dieser wird aus den Analysen deutlich, die eine durch die Kammer bestellte Kommission nach Auswertung der „professions de foi“ aller im Herbst 1919 angetretenen Listen vorlegte. Erstmals präsentierte der so im Juli 1920 zustandegekommene „Rapport Marin“ auch die Wahlaussagen der nicht gewählten Bewerber, um Minderheitsmeinungen zum Ausdruck kommen zu lassen. Ganz in der Tradition der „Barodets“ der Vorkriegszeit blieb der wichtigste Anstoß für die Zusammenstellung auch nach 1918 die stärkere Anbindung der Kammer an den Wählerwillen: „Pour maintenir le souvenir de nos engagements et stimuler, à leur endroit, notre activité, pour armer le contrôle de la Nation, un Barodet est souhaitable. Il serait plus souhaitable encore de pouvoir, au bout de quatre années d'efforts, l'apporter au corps électoral si celui-ci pouvait dire: ,Voilà vos promesses: je reconnais qu'elles sont réalisées"“.15

Die Liste Reynauds reflektierte in ihren wesentlichen Aussagen den im Bericht umschriebenen Kernbestand, den sie im Département vertrat. So entsprach sowohl die grundlegende Reformstimmung des Programms wie dessen antibolschewistische Ausrichtung oder die Forderung nach überparteilicher Solidarität vor der Aufgabe des materiellen und geistigen Wiederaufbaus einer allgemeinen Tendenz in den Wahlprogrammen des Bloc national. Dort fand sich regelmäßig die Betonung von Solidarität statt Klassenkampf, von öffentlicher Ordnung, Privatbesitz, die Akzeptanz einer in legalen Bahnen bleibenden Gewerkschaftsbewegung, die Forderung nach Reform der parlamentarischen Geschäftsordnung und nach Entflechtung der Gewalten. Auch mit spezielleren Wünschen im Hinblick auf die Modernisierung der Landwirtschaft stand die Liste Reynauds nicht allein,

Législature. Impressions. Projets de lois, propositions, rapports, etc. Tome XIX, No. 1431 (Programmes électoraux), Paris 1924, S. 174.

Allgemein zum „Bloc national“: Mayeur, Troisième République“, S. 254-256; Jean-Jacques Bekker/Serge Berstein, Victoire et frustrations 1914-1929 (Nouvelle histoire de la France contemporaine 12), Paris 1990 , S. 188-190.

it Vgl. „Appell du 22 octobre 1919“, in: Impressions XIX, S. 174.

15 „Rapport fait au nom de la commission chargée de réunir et de publier les programmes et engagements électoraux des candidats aux élections législatives de novembre 1919, par M. Louis Marin, Député", in: Chambre des Députés. Douzième Législature. Impressions. Projets de lois, propositions, rapports, etc. Tome XIX, No. 1431 (Programmes électoraux), Paris 1924, S. 1-232, hier: S. 13.

Ausdrückliches Ziel der Zusammenstellung und Analyse von „professions de foi“ war es schon vor dem Ersten Weltkrieg gewesen, „d'examiner les voeux de la nation consultée, dans des conditions de sécurité suffisante" (Ebenda, S. 12). Bestrebungen aus Parlamentarierkreisen, über die Erfassung der Wahlprogramme einzelner Kandidaten und ganzer Listen ein Abbild der „volonté nationale" zu gewinnen und die Kontrollfunktion des "corps électoral" zu stärken, reichen bis in die Zeit der Assemblée Constituante von 1789 zurück. Der erste, im offiziellen Auftrag der Kammer erstellte Bericht dieser Art, der „Rapport Pelletan“ datiert aus dem Jahre 1882. Er kam zustande, nachdem die hartnäckigen Bemühungen des wichtigsten nachrevolutionären Initiators dieser Idee, des Abgeordneten Désiré Barodet, sich gegen Bedenken einer Reihe von parlamentarischen Gegnern hatten durchsetzen können. Jene wollten durch das Verfahren die Gewissens- und Handlungsfreiheit der Abgeordneten gefährdet sehen und befürchteten die indirekte Einführung des imperativen Mandats. Die Tradition der regelmäßig erstellten und nach ihrem Begründer bald „Barodet“ genannten Kommissionsberichte wurde nach dem Ersten Weltkrieg auf Vorschlag der Parlamentarier Louis Marin und Georges Bonnefous wiederaufgenommen. 
ebensowenig wie mit der Forderung nach strikter Ausführung des Versailler Vertrags. Ein Programmpunkt stach indes heraus: Die vorgeschlagene Einführung der Kapitalsteuer und die Anhebung der Einkommensabgabe bei Bessergestellten bis zu einem Satz von 50 Prozent [!] unter Appell an den „patriotisme fiscal“ der Betroffenen unterstrich die Nähe der Liste zu linksrepublikanischen Positionen, die überdies bereits durch die Aufnahme eines radikalsozialistischen "co-listiers", des Abgeordneten Raoul Anglès, zum Ausdruck gekommen war. ${ }^{16}$ Die Handschrift des Listenmitglieds Reynaud ist an dieser Schlüsselstelle des Programms unverkennbar, auch wenn nun die bourgeoisie-kritische Komponente im Vergleich zu seinen Wahläußerungen des Jahres 1914 stark zurückgenommen worden war. Wiederum stand Reynaud durch die Punkte, die er (mit)vertrat, der radikalsozialistischen Position nahe: Die "Liste Radicale-Socialiste" des Départements wies programmatisch tatsächlich in den zentralen Fragen keine markanten Alternativen auf zu den Vorschlägen seiner Kandidatengemeinschaft, die zweifellos am linken Rand des durch den „Bloc national“ umrissenen Spektrums anzusiedeln war. ${ }^{17}$

Bemerkenswert ist, daß weder für die organisatorische Abwicklung noch für die programmatische Ausrichtung des Wahlkampfes, den Reynaud im Herbst 1919 führte, das parteipolitische Element im engeren Sinne eine erkennbare Rolle spielte. In keinem der Wahlmanifeste seiner Liste wurde auf eine der bestehenden Parteien Bezug genommen, die Parteizugehörigkeit des radikalsozialistischen Mitkandidaten wurde in den eigenen Verlautbarungen nicht thematisiert. Kein Mitglied seiner Liste schließlich war parteipolitisch aktiv in der wichtigsten und ihr programmatisch am nächsten stehenden Vertretung des nicht-radikalen Liberalismus, der „Alliance Républicaine Démocratique“.18 Ausschlaggebendes Kriterium für den Zusammenschluß der „Liste d'Union et de Concentration Républicaine" war nicht die gemeinsame Parteizugehörigkeit; maßgeblich war das wahltaktische Kalkül ihrer Gründer ebenso wie deren grundsätzliche Übereinstimmung im Hinblick auf die Restabilisierung der kriegsgeschwächten französischen Republik unter demokratischen und antikollektivistischen Vorzeichen. Ein solcher Konsens war sicherlich schon aufgrund seiner Weite nur von beabsichtigt geringer Bindekraft für seine Träger. Auch gelang es damit keineswegs, in der Konkurrenz zwischen den bürgerlichen Listenverbindungen unverwechselbares Profil zu zeigen. Insofern hatten die Wahldeklarationen der nichtsozialistischen

16 Zu dessen Parteizugehörigkeit vgl. Reynaud, Mémoires I, S. 131.

17 Das Wahlprogramm der radikalsozialistischen Liste findet sich in: Impressions XIX, S. 42 f.

18 Die Angaben des Parteiblattes La République Démocratique in dieser Frage sind widersprüchlich, lassen aber diesen Schluß zu. So figurieren im November 1919 unter der Rubrik "Nos candidats" für das Département Basses-Alpes die Kandidaten André Honnorat und Joseph Reinach irrigerweise als Mitglieder einer gemeinsamen Liste der „Alliance“ (La République Démocratique, 9. 11. 1919). Nach den Wahlen allerdings taucht für das Département kein siegreicher Kandidat der „Alliance“ auf, weder auf einer "Liste des Adhérents de l'Alliance, élus le 16 novembre et ayant reçu son investiture“ noch auf einer "Liste des candidats investis par l'Alliance ou élus sur son programme, bien que ne figurant pas encore sur ses contrôles“ ("Les élus de l'Alliance Républicaine Démocratique ", in: ebenda, 23.11. 1919).

(Das Parteiblatt der „Alliance“ wechselte zweimal seinen Namen: Nannte es sich zwischen 1902 und 1921 L'Alliance Républicaine Démocratique, trug es bis 1930 die Bezeichnung La République Démocratique, bevor es in L'Alliance Démocratique umbenannt wurde). 
Gruppen in der politischen Auseinandersetzung zwar mobilisierende, doch nur begrenzt strukturierende Kraft und Funktion. Darauf kam es den Kandidaten aber auch gar nicht in erster Linie an. Es ging vielmehr darum, die allgemeine Tendenz ihres politischen Engagements zu signalisieren und über die Kooperation mit regional bekannten Honoratioren zu untermauern. Als Erfolgsrezept war die Präsenz dreier bereits etablierter Volksvertreter auf der Liste Reynauds von mindestens ebenso großer Bedeutung wie die Formulierung des gemeinsamen Wahlprogramms. ${ }^{19}$

Das neue Wahlrecht hatte die Ausrichtung der Listenprogramme auf Fragen von stärker überregionaler Tragweite zweifellos gefördert: Auch Reynauds Liste stellte die "großen“ Probleme in den Mittelpunkt. Die prekäre Lage im Département trat demgegenüber in den Hintergrund und spiegelte sich nur indirekt in den Forderungen wider. ${ }^{20}$ Nicht erreicht worden war dagegen die Abkehr vom Prinzip persönlichkeitsorientierter Bewerbungen zugunsten eines Mehr an Parteiendemokratie - eines der Ziele der Verfechter des Verhältniswahlrechts. Noch 1919 zeigte der Verlauf des nationalen Wahlgangs in Frankreich bei allen regionalen Differenzierungen starke Züge der Persönlichkeitswahlen früherer Jahrzehnte. Die Bedeutung von „informellen Strukturen“, von Verwandtschafts- und Klientelbeziehungen für den Karriereverlauf der bürgerlichen politischen Eliten dominierte noch weithin und wurde erst allmählich überlagert durch das zunehmende Gewicht modernerer, institutionsgebundener Rekrutierungsmechanismen. ${ }^{21}$ Mit den Strukturen erwiesen sich die politischen Mentalitäten als außerordentlich zählebig, und dies traf auch zu für jene, die wie Paul Reynaud antraten, das politische System zu reformieren.

Nach einem insgesamt wenig lebendigen Wahlkampf ohne Höhepunkte oder größere Wahlveranstaltungen ${ }^{22}$ erreichte die Liste Reynauds bei der Abstimmung am 16. November 1919 einen klaren Sieg. Von insgesamt 22233 aktiven Wählern erhielt sie 48957 Stimmen und konnte damit absolut wie auf die Zahl ihrer Mitglieder bezogen mit Abstand das beste Ergebnis verbuchen: Von den fünf Abgeordneten des Départements stellte sie alleine drei. Paul Reynaud hatte seinen Abgeordnetensitz den Überresten des Mehrheitsprinzips im neuen Wahlmodus zu verdanken. $\mathrm{Da}$ ein Listenmitglied, der Publizist Raoul Anglès, die absolute Mehrheit der Stimmen auf sich hatte vereinen können, erhielt die Liste drei statt der ihr rechnerisch zustehenden zwei Mandate. Paul Reynaud zog als dritter erfolgreicher Bewerber der "Liste d'Union et de Concentration Républicaine“ in die erste französische Nachkriegskammer ein. ${ }^{23}$

19 Allgemein zur Charakteristik der Wahlen vom November 1919 im nationalen Rahmen: Nicolas Roussellier, Le parlement de l'éloquence. La souveraineté de la délibération au lendemain de la Grande Guerre, Paris 1997, S. 24-37.

20 Impressions XIX, S. 31. Die Tendenz zur Verlagerung der programmatischen Ansätze auf die nationale Ebene beobachtete der „Rapport Marin“: Impressions XIX, S. 15.

21 Roussellier, Parlement de l'éloquence, S. 35 f.; Heinz-Gerhard Haupt, Sozialgeschichte Frankreichs seit 1789, Frankfurt a.M. 1989, S. 211-218 (Zitat: 215).

22 So das rückblickende Urteil Reynauds: Reynaud, Mémoires I, S. 130-133.

23 Wäre die Mandatsverteilung nach reinem Verhältniswahlrecht vorgenommen worden, so hätte ein Konkurrent den Platz Reynauds erhalten. Zu den Wahlergebnissen und der genannten Alternative vgl. Lachapelle, Elections législatives du 16 Novembre 1919, S. 46-48. 


\section{Die Idee des Weges zwischen den Extremen: Paul Reynauds reparationspolitische Vorstöße 1921-1923}

Die Frage der einzuschlagenden deutschlandpolitischen Orientierung Frankreichs hatte im Wahlkampf Reynauds keine Rolle gespielt. Auch trat das Verhältnis Frankreichs zu seinem deutschen Nachbarn für Paul Reynaud nie in dem $\mathrm{Maße}$ in den Mittelpunkt seiner Tätigkeit wie etwa für seinen langjährigen Parteifreund in der "Alliance Républicaine Démocratique“, André François-Poncet. Dennoch begleitete Reynaud die Deutschlandpolitik Frankreichs über die Jahrzehnte hinweg zunächst als kritischer Beobachter und Kommentator, wurde dann aktiv als Vermittler und Mitgestalter, bevor er als Ministerpräsident 1940 das Erbe einer Politik antrat, deren Folgen er ab 1938 nur teilweise hatte mildern können. Weniger aus Neigung oder Affinität zum deutschen Nachbarn denn aus klarer Einsicht in die Bedingungen für den Wiederaufbau Europas nach dem Ersten Weltkrieg und in die Interdependenz von Siegern und Besiegten bezog er bereits in den frühen zwanziger Jahren dezidiert Stellung zugunsten einer kontrollierten Annäherung.

Es lag nahe, daß der Wirtschaftsexperte Reynaud, der seit seiner halboffiziellen Mission auf dem amerikanischen Kontinent vom Herbst 1920 über erste Erfahrungen im Bereich internationaler Finanzverhandlungen verfügte, sich mit dem Reparationsproblem auch jener Frage zuwenden würde, die bis weit in die zwanziger Jahre hinein die Beziehungen Frankreichs zu Deutschland dominierte.

Im März 1922 gab er sich in einem beiderseits des Rheins aufmerksam zur Kenntnis genommenen Artikel in der rechtsstehenden Zeitung Le Matin als Anhänger einer Regelung der französischen Reparationsforderungen über Aktienbeteiligungen an der deutschen Industrie zu erkennen ${ }^{24}$, nachdem er bis dahin mehrmals öffentlich für den Wiederaufbau der zerstörten Regionen durch deutsche Sachlieferungen und Arbeitsleistungen eingetreten war. ${ }^{25}$ Beide Lösungen waren zwar bereits seit den Versailler Friedensvertragsgesprächen immer wieder diskutiert worden, letztere hatte mit den Wiesbadener Abmachungen vom Oktober 1921 und dessen Folgevereinbarungen sogar Eingang in deutsch-französische vertragliche Regelungen gefunden; mehrheitsfähig waren diese Konzepte jedoch weder in Deutschland noch in Frankreich geworden. Nichtsdestoweniger stellten Bestrebungen zur Anbahnung der direkten Kooperation beider Länder und zur Einbettung des Reparationsproblems in den gesamteuropäischen Wiederaufbau, wie sie in den Plänen von Louis Loucheur, Emile Haguenin, Jacques Seydoux und schließlich auch von Paul Reynaud zum Ausdruck kamen, einen „bedeutende[n] Strang" in der französischen Reparationspolitik dar, der sich etwa bis Mitte 1922 in Konkurrenz zu einer unnachgiebigeren Linie behaupten konnte. ${ }^{26}$

24 Le Matin, 14. 3. 1922.

25 So etwa in "Comment faire payer l'Allemagne?", in: Journal de Barcelonnette, 1. 9. 1921; "L'exécution, la turquification, la Ruhr ou une nouvelle politique?", ebenda, 26.11.1921.

26 Auf die Defizite bei der Erforschung dieser Tendenz weist hin: Clemens A. Wurm, Frankreich, die Reparationen und die interalliierten Schulden in den 20er Jahren, in: Gerald D. Feldman (Hg.), Die Nachwirkungen der Inflation auf die deutsche Geschichte 1924-1933 (Schriften des Historischen Kollegs, Kolloquien 6), München 1985, S. 315-334, hier: 320f. (Zitat: S. 320). 


\section{a) Vorschläge für den Ausbau der Sachlieferungsoption}

Bereits im Januar 1921 hatte sich Reynaud vor der Finanzkommission der Chambre des Députés, der er nach seiner Reise durch den amerikanischen Kontinent unter anderem über seine Eindrücke von der aktuellen Finanzsituation in den USA berichtete, für ein deutsch-französisches Sachlieferungsabkommen zur direkten Beseitigung der Kriegsschäden in den „régions dévastées“ und zur Entlastung des französischen Staatshaushalts ausgesprochen. ${ }^{27}$ Während der fünftägigen Parlamentsdebatte um den Londoner Zahlungsplan vom Mai 1921 nahm Reynaud als Sprecher einer überparteilichen Gruppe von Abgeordneten der Mitte und der Rechten, zu der unter anderem Charles Reibel, Edouard de Warren, Pierre Taittinger, Edouard Soulier, Marcel Plaisant und Georges Bonnefous zählten, in einer Intervention erneut in diesem Sinne Stellung.

Die Beschlüsse der Londoner Konferenz der Alliierten (30. April - 5. Mai 1921), die der deutschen Regierung in ultimativer Form am 5. Mai übermittelt wurden, hatten das Reparationsproblem auf eine neue vertragliche Grundlage gestellt, die bis zur Annahme des Dawes-Planes 1924 maßgeblich bleiben sollte. Es war damit nach den vergeblichen Anläufen von Spa und Brüssel gelungen, das im Versailler Vertrag formulierte Gebot auf Festlegung einer fixen Reparationsforderung einzulösen und die deutsche Führung, die noch den Pariser Zahlungsplan vom 29. Januar 1921 abgelehnt hatte, nach der Besetzung mehrerer westdeutscher Industriestädte zur Annahme am 11. Mai 1921 zu bewegen. ${ }^{28}$ Aufgrund französischer Kompromißbereitschaft und englischen Insistierens sah der Londoner Reparationsplan, dem sich nach einigem Zögern die interalliierte Reparationskommission angeschlossen hatte, eine für die deutsche Seite deutlich günstigere Regelung vor, als sie noch im Januar 1921 festgelegt worden war. Anstelle der zunächst angestrebten 42 festen und variablen Annuitäten, die sich von zwei Milliarden Goldmark rasch auf sechs Milliarden steigern und außerdem 12,5\% aller deutschen Exporte umfassen sollten, forderte man nun feste Annuitäten von zwei Milliarden Goldmark und variable Jahresleistungen, die allmählich von 12,5\% auf $26 \%$ der deutschen Ausfuhren anwachsen würden. Statt einer Gesamtsumme von 226 Milliarden Goldmark ${ }^{29}$ waren nunmehr Bonds im Werte von 132 Milliarden durch Deutschland zu bezahlen, die sich in ihrem Ertrag vermutlich noch einmal vermindert hätten. ${ }^{30}$

27 Vgl. u.a. den Bericht „Aux Etats-Unis. Les Conséquences d'une Politique d'Isolement“, in: Journal de Barcelonnette, 9.1.1921.

28 Zum Verlauf der interalliierten Reparationsverhandlungen von den Beratungen im Vorfeld des Versailler Vertrags bis zum Londoner Ultimatum vgl. Marc Trachtenberg, Reparation in World Politics. France and European Economic Diplomacy, 1916-1923, New York 1980, S. 1-211.

29 Zur Berechnung dieses vermutlichen Ertrags des Pariser Reparationsplans vgl. Etienne Weill-Raynal, Les réparations allemandes et la France, 3 Bände, Paris 1947, hier: Band I, S. 680-682. Trachtenberg gibt keine genauen Zahlen (Trachtenberg, Reparation, S. 189); zur Problematik der Erstellung und des Vergleichs von Zahlenangaben zu den von den Alliierten geforderten Reparationssummen siehe Peter Krüger, Das Reparationsproblem der Weimarer Republik in fragwürdiger Sicht. Kritische Überlegungen zur neuesten Forschung, in: VfZ 29 (1981), S. 21-47, bes. S. 23-30.

30 Vgl. Trachtenberg, Reparation, S. 188f. und 210f; zur Forschungsdiskussion um den Wert der tatsächlich aufgrund des Londoner Zahlungsplans durch Deutschland zu erbringenden Leistungen: Ebenda, S. 385, Anm. 85. 
Mühsam nur und gegen große Bedenken in der Kammer war es der seit Januar 1921 amtierenden Regierung Briand gelungen, in der Debatte um die Beschlüsse der Pariser Reparationskonferenz insbesondere die Abgeordneten der Mitte und der Rechten von der Notwendigkeit der gemachten Zugeständnisse zu überzeugen und ein Vertrauensvotum des Parlaments zu erreichen. ${ }^{31}$ Als besonders hinderlich hatte sich dabei die Tatsache erwiesen, daß der politische Schwerpunkt des Kabinetts im Bereich der linken Mitte lag und damit nicht der weiter rechts anzusiedelnden Grundtendenz der Kammer entsprach. ${ }^{32}$ Entsprechend schwierig gestaltete sich die Kammeraussprache über den reduzierten Londoner Zahlungsplan. Da erstmals eine durch Deutschland akzeptierte, in Gesamtsumme und Zahlungsmodus festgelegte Reparationsregelung zur Debatte stand, gerieten die Kammersitzungen vom 19., 20. und 24. bis 26. Mai zu einer der ersten größeren deutschland- und reparationspolitischen Grundsatzdebatten der Chambre des Députés.

Ministerpräsident Briand, der der Kammer den genauen Text der Vereinbarungen nicht zur Kenntnis gebracht und auch nicht in Form eines Gesetzesvorschlags zur Ratifizierung vorgelegt hatte, zielte auf ein Vertrauensvotum durch einfachen Ordre du Jour. Der Kern der Reparationslösung, die er zusammen mit seinem Minister für die befreiten Regionen, Loucheur, vortrug, bestand in der Anwendung der in London beschlossenen Zahlungsmodalitäten durch die Mobilisierung der deutschen Schuld. Die deutschen Obligationen sollten an Käufer in aller Welt veräußert und somit die Last der Schuldeneintreibung durch ihre Internationalisierung verteilt werden. Hinter dem schließlich erreichten scheinbar eindeutigen Votum von 419 gegen 171 Stimmen $^{33}$ zugunsten dieses Vorgehens stand indessen eine in sich äußerst uneinige Kammer, die allein über acht verschiedene Ordres du Jour zu befinden hatte. Hinsichtlich der Lösung des Reparationsproblems zeichneten sich drei große Strömungen ab: Die "droite clemenciste" mit ihrem wichtigsten Sprecher André Tardieu, der sich seit 1919 unermüdlich als Verfechter einer orthodoxen Auslegung des Versailler Vertrages hervorgetan hatte ${ }^{34}$, stand für die kompromißlose Ablehnung der Londoner Vereinbarungen und eine Politik des Zwangs und der Faustpfänder, die im Bedarfsfalle insbesondere durch die Besetzung des Ruhrgebiets eingelöst werden sollte. Demgegenüber befürwortete eine „schweigende“", keinen Debattenredner stellende, doch umfangreiche Gruppe, die sich um François Arago, den Fraktionsführer der stärksten, am rechten Rand des „Bloc National“ stehenden Kammergruppe „Entente Républicaine Démocratique " scharte, in einem letztlich von der Kammermehrheit akzeptierten Ordre du Jour den Regierungsstandpunkt und mit ihm die Londoner Verhandlungsergeb-

31 Vgl. Bonnefous, Histoire politique III, S. 224-229.

32 Jean-Marie Mayeur, La vie politique sous la Troisième République, 1870-1940, Paris 1984, S. 264.

33 JO, Chambre des Députés, Débats parlementaires, Séance du 26 mai 1921, S. 2430 . Bonnefous, Histoire III, S. 238 gibt versehentlich ein Abstimmungsergebnis an, das sich nur auf einen Teil des schließlich verabschiedeten Ordre du Jour bezieht.

34 Vgl. Rudolph Binion, Defeated Leaders. The Political Fate of Caillaux, Jouvenel, and Tardieu, New York 1960, S. 285 f. Die erste, auf die verfügbaren archivalischen Quellen gestützte biographische Studie zu Tardieu - François Monnet, Refaire la République. André Tardieu, une dérive réactionnaire (1876-1945), Paris 1993 - legt ihren Schwerpunkt auf den Innen- und Reformpolitiker und behandelt die deutschlandpolitischen Ideen und Aktionen Tardieus nur am Rande. 
nisse. ${ }^{35}$ Eine dritte Strömung schließlich ${ }^{36}$, getragen von den Sozialisten und von gemäßigten Abgeordneten aus dem breiten parlamentarischen Mittelfeld zwischen der radikalsozialistischen Fraktion und der „Entente Républicaine Démocratique", optierte für einen Kompromiß: Man lehnte teils aus grundsätzlichen, teils aus ganz praktischen Gründen den Londoner Zahlungsplan ab, bemühte sich aber andererseits, gangbare Alternativen zu präsentieren, die eine Zwangspolitik überflüssig machen konnten. Das Schwergewicht in den durch die Debattenredner Pierre Forgeot, Vincent Auriol, Georges Noblemaire, Maurice de Rothschild und Paul Reynaud entwickelten Vorschlägen lag bei deutschen Sachlieferungen, die man nicht nur aufgrund des komplexen Transferproblems favorisierte, dessen Tragweite man erkannt hatte. Die Haupteinwände richteten sich gegen den Kern der Londoner Vereinbarungen: Man bezweifelte die Mobilisierbarkeit der deutschen Obligationen, deren Attraktivität für ausländische Bankiers von der Stabilität der deutsch-französischen Beziehungen abhängen mußte (Auriol ${ }^{37}$ ), wies hin auf den Widerspruch zwischen der notwendigen Steigerung deutscher Exporte zur Erfüllung der Zahlungsverpflichtungen und zunehmenden Zollbarrieren in Europa einerseits, dem französischen Interesse an der Entwicklung der eigenen Exporte andererseits (Forgeot, Auriol ${ }^{38}$ ), und man machte klar, daß die Londoner Beschlüsse ein deutsches Unterlegenheitsverhältnis gegenüber Frankreich zugrundelegten, das nicht über Jahrzehnte hinweg aufrechtzuerhalten sei (Forgeot, Reynaud ${ }^{39}$ ).

Als letzter planmäßiger Debattenredner erläuterte Paul Reynaud einen Entschließungsantrag auf Neuverhandlung des Londoner Zahlungsplanes, den er als Wortführer einer Gruppe von 28 Abgeordneten der parlamentarischen Mitte vorgelegt hatte. Er faßte dabei nochmals die wichtigsten Vorteile der "prestations en nature" zusammen. 40 Wie seine Vorredner Auriol und Forgeot zeigte sich Reynaud überzeugt, daß als Alternative zu langfristig angelegten und von unkalkulierbaren politischen Wechselfällen abhängigen Annuitäten allein Sachlieferungen die Chance böten, den raschen Wiederaufbau der zerstörten Regionen Nordostfrankreichs zu ermöglichen und diese wichtigen Industriegebiete möglichst schnell wieder in das französische Wirtschaftsleben zu integrieren; weder neue Steuern noch Anleihen könnten die dazu erforderlichen Summen erbringen. ${ }^{41}$

35 Zum Text des ausschließlich von Abgeordneten der Fraktion „Entente Républicaine Démocratique " unterzeichneten und von der Kammer verabschiedeten Ordre du Jour: JO, Chambre des Députés, Débats parlementaires, Séance du 26 mai 1921, S. 2417 und 2430.

36 Bonnefous, Histoire III, S. 237 f. hebt in seiner Darstellung des Debattenverlaufs lediglich zwei Tendenzen hervor und übergeht sowohl die „Entente Républicaine Démocratique“ und ihren befürwortenden Ordre du Jour als auch die bedingte Zustimmung der gemäßigten Mitte. So gelangt er zu der irreführenden Behauptung, die Linke habe die Außenpolitik Briands am energischsten unterstützt und übersieht dabei, daß Sozialisten und Radicaux alleine niemals die schließlich erreichte Zahl von über 400 Stimmen hätten mobilisieren können.

37 JO, Chambre des Députés, Débats parlementaires, Séance du 24 mai 1921, S. 2364-2369, hier: S. 2368.

38 Ebenda, Séance du 20 mai 1921, S. 2339-2346, hier: S. 2342 f. (Forgeot); ebenda, Séance du 24 mai 1921, S. 2368 (Auriol).

39 Ebenda, Séance du 20 mai 1921, S. 2345 (Forgeot); ebenda, Séance du 26 mai 1921, S. 2428 (Reynaud).

40 Ebenda, Séance du 26 mai 1921, S. 2427 f.

41 Ebenda, S. 2428. Die gleiche Argumentation findet sich auch in den Beiträgen von Forgeot und Auriol: Ebenda, Séance du 20 mai 1921, S. 2343 f. bzw. ebenda, Séance du 24 mai 1921, S. 2367 f. 
Eben jene deutschen Wiederaufbauleistungen aber, die durch ihre Anrechnung auf die letzte und unsicherste Tranche von Obligationen eine unverzügliche Mobilisierung der deutschen Schuld erbringen könnten, würden durch die Londoner Regelungen praktisch unmöglich gemacht. ${ }^{42}$ Unter Beifall faßte er in gewohnter Prägnanz seinen Eindruck von der hinter diesem Verhandlungsergebnis stehenden allzugroßen Rücksichtnahme der Regierung Briand auf die heimische Industrie und deren Interesse am Wiederaufbaugeschäft zusammen:

„Nous savons qu'il y a des intérêts puissants qui sont opposés à la réparation en nature. (Applaudissements sur divers bancs à l'extrème gauche, à gauche et sur divers bancs au centre et à droite.) Nous savons qu'il y a les profiteurs de la reconstruction, comme il y a eu les profiteurs de la guerre. Votre politique consiste à nous interdire pratiquement de nous adresser à l'Allemagne pour les réparations en nature". ${ }^{43}$

$\mathrm{Daß}$ jedoch im Zweifelsfalle die Bedürfnisse der zerstörten Regionen und die Beseitigung von Produktionsengpässen Vorrang hätten vor den Interessen der intakten Produktionsstätten in Kernfrankreich, daran ließ Reynaud ebensowenig Zweifel wie vorher schon Forgeot, Auriol und de Rothschild. ${ }^{44}$

Wenn die Entschließungsanträge, die den Londoner Zahlungsplan im Sinne jener Reparationslösung modifiziert wissen wollten, nicht zum Zuge, ja nicht einmal zur Abstimmung kamen, dann lag dies wohl zu allererst daran, daß die Kammermehrheit nicht bereit war, durch die Infragestellung der Londoner Vereinbarungen den Bruch mit den englischen Alliierten in Kauf zu nehmen.45

Das Verhalten der "modérés" in der Debatte um die Londoner Vereinbarungen vom Mai 1921 zeigt, wie wenig das Bild eines homogenen „Bloc National“ auch auf dem Feld der Deutschlandpolitik der parlamentarischen Wirklichkeit tatsächlich entsprach. Neben einem hauptsächlich durch die Abgeordneten der „Entente Républicaine Démocratique“ getragenen rechten Flügel, welcher es sich zur Regel gemacht hatte, die Außenpolitik der durch den „Bloc National“ gestellten Regierungen zu stützen ${ }^{46}$ - nicht ohne jedoch Briand in seinem Vertrauensvotum auf eine entschlossene Deutschlandpolitik zu verpflichten -, trat innerhalb der Mehrheit eine weitere, heterogene Strömung hervor, die sich in reparationspolitischer Hinsicht als außerordentlich innovativ erwies. Ohne Berührungsängste mit sozialistischen Konzepten, auf die man sich teilweise sogar berief47, favorisierte man eine bis dahin zwar in Expertenkreisen immer wieder ins Auge gefaßte, doch im internationalen politischen Kontext noch kaum umgesetzte Variante der Repara-

42 Ebenda, Séance du 26 mai 1921, S. 2427f. Artikel 10 der Londoner Vereinbarungen erlaubte Sachleistungen zwar grundsätzlich, machte sie aber durch die Auflage ihrer Bezahlung in Gold oder nächstfälligen Coupons für die französischen Geschädigten uninteressant. Die Kritik an diesem Passus findet sich ebenso bei de Rothschild und Auriol (Ebenda, Séance du 24 mai 1921, S. $2368 \mathrm{f}$. (Auriol), ebenda, Séance du 26 mai 1921, S. 2423 (de Rothschild)).

43 JO, Chambre des Députés, Débats parlementaires, Séance du 26 mai 1921, S. 2427 f.

44 Ebenda, Séance du 20 mai 1921, S. 2344 f. (Forgeot); ebenda, Séance du 26 mai 1921, S. 2423 f. (de Rothschild).

45 Bonnefous, Histoire III, S. $237 \mathrm{f}$.

46 Carrère/Bourgin, Manuel, S. 66.

47 So zeigten Forgeot (JO, Chambre des Députés, Débats parlementaires, Séance du 20 mai 1921 , S. 2344), Noblemaire (Ebenda, Séance du 25 mai 1921, S. 2384) und de Rothschild (Ebenda, Séance du 26 mai 1921, S. 2423) Sympathien für die Vorschläge Auriols. 
tionspolitik. In Frankreich wie in Deutschland innenpolitisch umstritten, stellte die Sachlieferungsoption auch in den zwischenstaatlichen Verhandlungen ein „heißes Eisen“ dar.

Zwar hatte der Versailler Vertrag in seinen Artikeln 235 und 236 sowie weiteren spezifizierenden Abschnitten ${ }^{48}$ grundsätzlich die Voraussetzungen für eine Begleichung der deutschen Reparationsschuld durch Sachlieferungen geschaffen, doch war die Regelung genauer Liefermengen und -modalitäten im wesentlichen den späteren Verhandlungen zwischen den Alliierten und Deutschland sowie der Festlegung durch die Reparationskommission überlassen worden. ${ }^{49}$ Die bald zerfallende reparationspolitische Einheit zwischen den Siegern und insbesondere zwischen Frankreich und Großbritannien machte die gemeinsame Durchführung dieser Bestimmungen indes bald unmöglich. Das sehr viel bedeutendere Ausmaß der Zerstörungen auf französischem Boden und die Tatsache, daß die britischen Sachforderungen mit der Übergabe deutscher Handelsschiffe rasch erfüllt worden waren, ließ das Interesse an einem Ausbau der Sachlieferungsoption im wesentlichen auf seiten der französischen Alliierten fortbestehen. Die britischen Erwartungen richteten sich in der Folge vorwiegend auf finanzielle Reparationsleistungen. Hinzu trat die britische Sorge um Absatzmärkte für die eigene Kohleproduktion, die ein genuin angelsächsisches Interesse an der Beschränkung deutscher Kohlelieferungen nach Frankreich schuf und eine deutsch-englische Interessenannäherung in dieser Frage zur Folge hatte. ${ }^{50}$

Die deutsche Seite zeigte sich gegenüber der Lösung des Reparationsproblems durch Sachlieferungen nicht abgeneigt, zog jedoch anstelle von Kohlelieferungen, die den Aufschwung der eigenen Stahlindustrie bremsen mußten, den auch für die heimische Wirtschaft förderlichen direkten Wiederaufbau der zerstörten Gebiete durch deutsche Unternehmer vor. ${ }^{51}$ Für den Bereich der Kohlelieferungen, deren Regelung überragende Bedeutung für den industriellen Wiederaufstieg Deutschlands wie Frankreichs zukam, war es bereits seit Ende 1918 zu Vereinbarungen gekommen. Sie waren als erste Schritte zur Wiederherstellung des kriegsbedingt unterbrochenen Austauschsystems von deutscher Kohle und französischen Eisenerzen gedacht. Bilaterale Wirtschaftsverhandlungen, bei denen man sich neben den großen alliierten Konferenzen teils auf Veranlassung der Regierungen, teils

48 Es handelt sich im einzelnen um Anhang III (Handelsschiffe), IV (Lieferungen in die „régions dévastées), V (Kohle und Koks) und VI (Chemieprodukte) in Teil VIII des Versailler Vertrags (WeillRaynal, Réparations I, S. 368 und 380).

Von den in diesen Abschnitten festgelegten Sachlieferungen im eigentlichen Sinne sind die hier nicht zu behandelnden Kategorien der Restitutionen, „livraisons d'armistice“ und des "matériel abandonné" zu unterscheiden (vgl. Weill-Raynal, Réparations I, S. 368-379).

49 Zum folgenden siehe Jacques Bariéty, Les relations franco-allemandes après la Première Guerre Mondiale. 10 Novembre 1918 - 10 janvier 1925, de l'Exécution à la Négociation, Paris 1977, S. 7682.

50 Vgl. hierzu: Christoph Stamm, Lloyd George zwischen Innen- und Außenpolitik. Die britische Deutschlandpolitik 1921/22, Köln 1977, S. 14 ff.; Bernd Dohrmann, Die englische Europapolitik in der Wirtschaftskrise 1921-1923. Zur Interdependenz von Wirtschaftsinteressen und Außenpolitik, München u. a. 1980, S. 71-84; Anne Orde, British Policy and European Reconstruction after the First World War, Cambridge 1990, S. $65 \mathrm{ff}$.

51 Bariéty, Relations, S. 81 f.; Peter Krüger, Deutschland und die Reparationen 1918/19. Die Genesis des Reparationsproblems in Deutschland zwischen Waffenstillstand und Versailler Friedensschluß (Schriftenreihe der Vierteljahrshefte für Zeitgeschichte 25), Stuttgart 1973, S. 172-174. 
auf Privatinitiative des Industriellen Hugo Stinnes mit dieser Frage beschäftigt hatte, blieben jedoch immer den Klimaschwankungen des allgemeinen, komplexen deutsch-französischen Verhältnisses unterworfen und brachten bis Sommer 1920 keine wesentlichen Fortschritte. Im Vorfeld der Konferenz von Spa im Juli 1920 war die Kohlenfrage aufgrund deutscher Rückstände bei den friedensvertraglich festgelegten Liefermengen in den Mittelpunkt des französischen Interesses getreten. Nun wurde jene Periode der durch beide Regierungen geförderten Wirtschaftsverhandlungen durch eine härtere französische Politik abgelöst, in der das Mittel des Ultimatums und der Sanktionsdrohung mindestens gleichgewichtig neben der fortbestehenden prinzipiellen Verhandlungsbereitschaft stand. 52

Die Idee des Wiederaufbaus der zerstörten französischen Regionen durch Einsatz deutscher Arbeitskräfte und Materialien andererseits, vorgesehen in Anhang IV des Versailler Vertrages, war bereits unmittelbar nach dessen Unterzeichnung zwischen Juli und Dezember 1919 Gegenstand deutsch-französischer Verhandlungen gewesen.

Der Arbeitskräfteeinsatz scheiterte indes an Differenzen über die Leitung der Wiederaufbaumaßnahmen vor Ort, an innerfranzösischen Widerständen sowie an der Änderung der innenpolitischen Situation in Frankreich nach Regierungsantritt des Bloc National. ${ }^{53}$ Die vorgesehenen Warenlieferungen ihrerseits kamen, auch nachdem die Reparationskommission ab Januar 1920 ihre Abwicklung zu erleichtern versuchte, de facto ebenfalls nur in einem für Frankreich enttäuschenden Ausmaß zustande. In einer Anfang November 1920 entstandenen „Note sur les paiements en nature" schätzte der Generalsekretär der französischen Delegation bei der Reparationskommission, Alexandre Aron, den jährlichen Ertrag allein der aufgrund Anhang IV des Versailler Vertrags den zerstörten Regionen zukommenden Sachlieferungen auf einen Wert von 634 Millionen Goldmark. Tatsächlich gingen im gesamten Zeitraum zwischen Ende 1919 und dem 1. Mai 1921 aufgrund dieses Artikels lediglich Waren im Wert von knapp 4 Millionen Goldmark an Frankreich. ${ }^{54}$ Verantwortlich hierfür waren sowohl Verzögerungen bei der Angebotserstellung durch die deutsche Regierung und Uneinigkeiten bei der Preisgestaltung als auch bis Sommer 1922 weitgehend fehlende Zollerleichterungen für die Geschädigten. Die allgemeine Vernachlässigung dieser Reparationsoption gegenüber Kohlelieferungen durch die französische Regierung kam erschwerend hinzu und begründete die Tatsache, daß vor 1921 keine effektive Organisation zur Bedarfsfeststellung und zur Verteilung der gelieferten Waren ins Leben gerufen

52 Einen ausführlichen, quellengestützten Überblick über die genannten Verhandlungen vom Waffenstillstand 1918 bis zum Wiesbadener Abkommen 1921 bietet: Peter Wulf, Hugo Stinnes. Wirtschaft und Politik 1918-1924 (Kieler Historische Studien 28), Stuttgart 1979, S. 169-221 und 241293, hier: S. 169-196.

53 Weill-Raynal, Réparations I, S. 442-444; Stephen D. Carls, Louis Loucheur and the Shaping of Modern France 1916-1931, Baton Rouge/London 1993, S. 180-182.

54 Weill-Raynal, Réparations I, S. $454 \mathrm{f}$. und 441. Weill-Raynal schätzt, daß von den zwischen 1919 und Ende 1922 durch Frankreich erbrachten Wiederaufbauleistungen im Umfang von etwa 19 Mrd. Goldmark nur ein Anteil von ca. 570 Millionen durch deutsche Sachlieferungen aller Art davon etwa 24 Millionen auf der Basis des Anhang IV - abgedeckt wurde: „Il apparaît donc que jusqu'à la période de l'occupation de la Ruhr et de la mise en vigueur du plan Dawes, l'utilisation des prestations en nature allemandes pour la reconstitution des régions dévastées a été pratiquement nulle" (ebenda, S. 470f.). 
wurde. Bis Sommer 1921 stützte sich der beginnende Wiederaufbau deshalb vorwiegend auf Waren heimischer und dritter Provenienz oder solche, die aufgrund privater Vereinbarungen zwischen französischen Interessenten und deutschen Anbietern in die zerstörten Gebiete gelangten. 55

Dabei standen dieser weitgehend ungenutzten Reparationsoption sowohl auf deutscher wie auf französischer Seite durchaus Ansätze für eine umfassende Lösung gegenüber. So hatte Hugo Stinnes in einer Unterredung mit dem französischen Ministerpräsidenten Millerand bereits im Juli 1920 vor der Konferenz von Spa unter anderem seine Vorstellungen von einem koordinierten Wiederaufbau der zerstörten Regionen zur Sprache gebracht; wegen anders begründeter Meinungsverschiedenheiten waren sie nicht weiter verfolgt worden. ${ }^{56}$ Stinnes, einflußreicher Vorsitzender des Reichsverbandes der deutschen Industrie, war bis Frühsommer $1920 \mathrm{zu}$ einem gewichtigen Berater bei der Formulierung der deutschen Reparationspolitik geworden, dessen Sachverstand und Urteil von beiden Parteien anerkannt wurden. ${ }^{57}$ Den gemeinsamen Wiederaufbau Nordostfrankreichs verstand er - nicht ohne konkrete geschäftliche Hintergedanken - als notwendige Vorbereitungsphase für eine allgemeine Entspannung der deutsch-französischen Beziehungen, deren Endziel die weitergehende wirtschaftliche Kooperation im Rahmen einer mitteleuropäischen Zollunion sein sollte. ${ }^{58}$

Im Verlauf der Gespräche von Spa, an denen Stinnes als Sachverständiger der Bergbauindustrie teilnahm, knüpfte die deutsche Delegation mit einem ausgearbeiteten Vorschlag an die abgebrochenen Gespräche des Jahres 1919 an. Sie präsentierte einen Rekonstruktionsplan, der den Ausbau der Sachlieferungsoption vorsah und die Initiative für die Durchführung des Wiederaufbauprogramms einem internationalen Unternehmerverbund zudachte. An eine Expertenkommission weitergegeben, wurden die Vorschläge, die den Interessen der französischen und englischen Industrie am Wiederaufbaugeschäft widersprachen, schließlich abgewiesen. ${ }^{59}$

Weitaus größeres Gewicht für den Verlauf der Reparationsverhandlungen bis zum Londoner Ultimatum erlangten hingegen die Konzeptionen, die der Leiter der Wirtschaftsabteilung im französischen Außenministerium, Jacques Seydoux, seit Spätsommer 1920 entwickelte. Wie einige andere französische Spitzenbeamte erkannte er die Vorteile, die deutsche Sachlieferungen für den raschen Wiederaufbau des Landes, die Entlastung des Staatshaushalts und die Verknüpfung der eigenen Rekonstruktionsanstrengungen mit dem deutschen Wiederaufschwung haben konnten. ${ }^{60}$ Mit politischer Rückendeckung durch Ministerpräsident Millerand, der eine „pragmatische Verständigungspolitik"61 Gewaltmaßnahmen vorzog,

55 Weill-Raynal, Réparations I, S. 446-452; hier auch ein Abriß der praktischen Schwierigkeiten, auf die die Lieferungen und ihre Anbahnung stießen sowie der Beratungen der Reparationskommission zu deren Behebung: ebenda, S. 453-472.

56 Wulf, Stinnes, S. $203 \mathrm{f}$.

57 Ebenda, S. 195.

58 Ebenda, S. $201 \mathrm{f}$.

59 Bariéty, Relations, S. 82. Die Protokolle der Unterredungen finden sich abgedruckt in: Documents on British Foreign Policy 1918-1939, First Series, Band VIII, S. 422-648. Vgl. auch Weill-Raynal, Réparations I, S. 562-578, hier: 569-571.

60 Bariéty, Relations, S. 83.

61 Krüger, Außenpolitik, S. 117. 
sollte durch die Kombination verschiedener Reparationsmöglichkeiten unter Betonung der Sachlieferungen eine vernachlässigte Reparationsquelle erschlossen werden. Die Mängel der bisherigen Praxis versuchte man insbesondere durch die Vereinfachung von Geschäftsbeziehungen zwischen Geschädigten und Lieferanten und eine günstigere Regelung der Preisfestsetzung auszugleichen. Bei der Reichsregierung wie bei der deutschen Industrie stieß man damit aber nur auf skeptische Resonanz. Der Sturz Millerands und der deutschlandpolitisch ebenfalls kompromißbereiten Regierung Leygues im September 1920 bzw. im Januar 1921 entzog den französischen Vorschlägen zunächst die innenpolitische Basis. ${ }^{62}$ Die Befürworter einer an den ökonomischen Realitäten orientierten Politik der Zusammenarbeit setzten ihre Bemühungen jedoch auch nach Regierungsantritt Briands fort, dessen vielgesichtige Deutschlandpolitik trotz aller zur Schau getragenen Aggressivität einige Zeichen für eine konziliantere Haltung erkennen ließ.63

In der Debatte um die Londoner Abmachungen vom Mai 1921 trafen so die wichtigsten in der Kammer vertretenen deutschlandpolitischen Positionen aufeinander und warben um die Zustimmung des Regierungschefs, über dessen Haltung sich weder die regierungstragende Mehrheit noch die Anhänger einer pragmatischeren Politik inner- und außerhalb des „Bloc national“ restlos im klaren waren. Das Konzept der "réparations en nature“ kristallisierte sich nun auf parlamentarischer Ebene als die wichtigste Alternativlösung zur Position der Regierung heraus. Louis Loucheur, der die Darlegung des Kabinettsstandpunkts für die finanziellen Aspekte der Londoner Vereinbarungen übernommen hatte, ging darauf jedoch in seiner Stellungnahme nur ausweichend ein: Er verwies auf die mangelnde Akzeptanz Hunderttausender deutscher Arbeiter in den betroffenen Regionen und die Gefahr der Etablierung deutscher Exporteure in Frankreich. „Fournitures en nature" hatten in seinen Plänen nur in einem zu den Interventionen Forgeots, Reynauds und Auriols konträren Sinne Platz: als Teil deutscher Exporte sollten sie dem Schuldner die nötigen Devisen für Barzahlungen verschaffen.64

Mit umso größerer Befriedigung nahmen deshalb die Initiatoren des parlamentarischen Vorstoßes um Reynaud die Aufnahme von deutsch-französischen Verhandlungen zur Kenntnis, die ab Juni 1921 zwischen dem neuen deutschen Minister für den Wiederaufbau, Rathenau, und Loucheur eingeleitet wurden und gerade jene alternativen Prinzipien ins Auge faßten, die in der Kammer so vehement diskutiert worden waren. Reynaud selbst verstand die Besprechungen, die auf deutsche Initiative und das Entgegenkommen Briands hin gegen einen mit Blick auf innerfranzösische Widerstände eher zögernden Loucheur zustande kamen ${ }^{65}$, als indirekte Bestätigung seines Entschließungsantrags und der dahinterstehenden Vorschläge.66 So ging er mit Beginn der Parlamentsferien daran, seine Reparationsvorstellungen in mehreren Artikeln fortzuentwickeln, zu verdichten und einer

62 Zum Seydoux-Plan: Krüger, Außenpolitik, S. 116-122; immer noch grundlegend: Georges Soutou, Die deutschen Reparationen und das Seydoux-Projekt 1920/21, in: VfZ 23 (1975), S. 237-270.

63 Krüger, Außenpolitik, S. 120.

64 Vgl. die Stellungnahme Loucheurs: JO, Chambre des Députés, Débats parlementaires, Séance du 20 mai 1921, S. $2347 \mathrm{f}$.

65 Carls, Louis Loucheur, S. $229 \mathrm{f}$.

66 Paul Reynaud, „L'accord de Wiesbade ou De la coupe du producteur allemand aux lèvres du sinistré français“, in: Journal de Barcelonnette, 1. 12. 1921. 
außerparlamentarischen Öffentlichkeit vorzustellen. Dabei erneuerte er seine Bedenken gegenüber den Londoner Regelungen und unterzog die französische Reparationspolitik als Ganze einer fundierten Kritik. Sie versuchte sowohl das komplizierte Neben- und Gegeneinander der alliierten Interessen als auch das Verhältnis zum deutschen Gläubiger realistisch zu erfassen und in ein zunächst nach wie vor auf Sachlieferungen ausgerichtetes Gesamtkonzept einzubinden.

Anstelle einer Politik ständig neuer Zugeständnisse gegenüber den Alliierten, die im Gegenzug nicht mehr als die nur widerwillig gewährte Erlaubnis zu Zwangsmaßnahmen einbrachte, sei eine wirtschaftspolitische, den Wiederaufbau Gesamteuropas berücksichtigende und nicht allein finanzpolitische Lösung erforderlich. Nur so könnten gleichermaßen die widerstreitenden handelspolitischen Interessen der Beteiligten befriedigt und die Ursachen des ständigen englischen Drucks auf Verminderung der deutschen Reparationssumme beseitigt werden. Die Schwerpunktverlagerung auf Sachlieferungen in Wiederaufbaugebiete könnte gleichermaßen dem deutschen Exportbedürfnis, der englischen und amerikanischen Furcht vor dem Überhandnehmen billiger deutscher Ausfuhrgüter auf dem Weltmarkt und dem französischen Bedarf an Fertigwaren und Baumaterial entgegenkommen. Überdies wäre auf diesem Umweg die in den Versailler Verhandlungen noch verweigerte Priorität für Reparationen an Frankreich zu erreichen. ${ }^{67}$

Mit großer Treffsicherheit erfaßte Reynaud die Schwächen der bis dahin durch die französische Politik anvisierten Standardlösungen, die auf freiwillige deutsche Zahlungen, auf eine effektive Tätigkeit der Reparationskommission oder auf die Besetzung des Ruhrgebiets setzten. Ausgehend von der präzisen Kenntnis der innenpolitischen Kräfteverhältnisse in Deutschland bezüglich der Reparationsfrage und anders als Briand, der öffentlich Vertrauen in den neuen Kanzler Wirth demonstrierte ${ }^{68}$, gab er sich keinen Illusionen über den Kern der deutschen Erfüllungspolitik und ihren Ertrag für Frankreich hin. Er begriff sie zu Recht als Revisionspolitik mit anderen Mitteln, die zunehmend auf englische Unterstützung und das Gewicht der Weltmeinung baute: „Exécuter? Il n'y a pas un Allemand en Allemagne disposé à exécuter intégralement l'état des paiements du mois de mai dernier, connu sous le nom de l'accord de Londres"69. Im Gegensatz zur großen Mehrheit der nichtsozialistischen Politiker Frankreichs aber lehnte er die These vom „betrügerischen Bankrott" ab. Ihr zufolge hielt die deutsche Regierung zur Umgehung der Verpflichtungen des Versailler Vertrags bewußt das Steueraufkommen niedrig und plante überflüssige Staatsausgaben ein, um eine Fassade der Bedürftigkeit zu schaffen, hinter der sich gleichwohl ein durch günstige Exporte auf den Weltmarkt erworbener Wohlstand verberge. ${ }^{70}$ Zwar erkannte der Finanz-

67 Paul Reynaud, „D'une politique d'application du Traité de paix en ce qui concerne les Réparations“, in: Revue Hebdomadaire, 13. 8. 1921, S. 214-225. Der Artikel wurde in seinen wesentlichen Inhalten in Reynauds Heimatdépartement publik gemacht unter dem Titel: „Comment faire payer l'Allemagne? La thèse de M. Paul Reynaud“, in: Journal de Barcelonnette, 1. 9. 1921.

$68 \mathrm{Vgl}$. dazu Bonnefous, Histoire III, S. $237 \mathrm{f}$.

69 Paul Reynaud, „Pour que l'Allemagne paie. L'exécution, la turquification, la Ruhr ou une nouvelle politique?", in: Journal de Barcelonnette, 15. 12. 1921.

70 Ein Bericht der deutschen Botschaft in Paris vom 20.9. 1921 resümierte die zentralen Elemente dieser in der Presse und Öffentlichkeit Frankreichs weitverbreiteten These: Zur Schwächung der Mark und zur Rettung von Devisen vor alliiertem Zugriff erhöhe die deutsche Regierung unablässig die umlaufende Geldmenge, placiere die Industrie ihre bei Vollbeschäftigung erzielten üppigen 
experte sehr wohl, daß man in Deutschland auf den seit Juni 1921 drastisch sich verschärfenden inflationären Markverfall spekulierte, um daraus wirtschaftlichen und politischen Gewinn zu ziehen. ${ }^{71}$ Er übersah deshalb aber nicht die Kehrseite jener Politik, durch die Deutschland nun seiner Ansicht nach wirtschaftlich bedeutend schlechter gestellt sei als noch vor 1914. Als belastend erkannte er etwa die hohen Zollschranken in ganz Europa, die den Export der inflationsbedingt billigeren deutschen Waren zunehmend erschwerten, die Warenknappheit in Deutschland selbst und nicht zuletzt die zunehmende soziale Krise zu Lasten vor allem der Mittel- und Unterschichten.72 Bemerkenswert sachkundig hielt Reynaud dem französischen Publikum die wichtigsten Faktoren vor Augen, die die Produktion nationalen Reichtums in Deutschland auf deutlich geringerem Niveau hielten, als es die äußerlich intensive Auslastung der Industrie vermuten ließ: Faktoren, die insofern die Fähigkeit des Reiches zu Reparationsleistungen vermindern mußten. Insbesondere die Verluste von Industrieregionen und landwirtschaftlichen Nutzflächen aufgrund von Gebietsabtretungen, die übermäßige Absorption von Arbeitskräften im öffentlichen Dienst, die Bindung industrieller Kapazitäten zur Versorgung des eigenen Landes sowie die Auswirkungen des Achtstundentages erkannte er zu Recht als Ursachen relativ schwacher deutscher Exportraten im Vergleich zur Vorkriegszeit und Auslöser einer klar negativen Handelsbilanz des Reiches für das Jahr 1921.73

Wie nur sehr wenige französische Politiker des bürgerlichen Spektrums äußerte er angesichts dieser Umstände dringende Zweifel, ob Deutschland bei einer voraussichtlichen Exportleistung von 7 Milliarden Goldmark im Jahr 1921 die durch den Londoner Zahlungsplan geforderten Summen tatsächlich in Devisen werde aufbringen können. Als Alternative empfahl er erneut, den undurchführbaren Londoner Plan zugunsten von Neuverhandlungen aufzugeben und, falls Großbritannien nicht bereit sei, die Lösung der "prestations en nature" mitzutragen,

Gewinne im Ausland und verweigerten potente Steuerzahler mit staatlicher Duldung ihre Leistungen, um zu Lasten insbesondere der kleinen Lohnempfänger bewußt auf den Staatsbankrott hinzuarbeiten (wiedergegeben nach: Gerald D. Feldman, The Great Disorder. Politics, Economics, and Society in the German Inflation, 1914-1924, New York u.a. 1993, S. 377 f.).

Diese Anschauung entsprach unter anderem auch den Berichten französischer Deutschlandreisender, die die Krisenerscheinungen hinter dem scheinbaren Wohlergehen nicht wahrnahmen (Vgl. etwa Albert Londres, „Nous occupons l'Allemagne et les Allemands nous occupent (Huit jours à Dusseldorf) “, in: Revue Hebdomadaire, 9. 4. 1921). Einem mit den wirtschaftspolitischen Gegebenheiten nicht vertrauten Beobachter mußten insbesondere die Zusammenhänge zwischen den inflationär sich steigernden Staatsausgaben und der real nahezu erreichten Vollbeschäftigung sowie der Steigerung der Produktion verborgen bleiben (dazu: Gerald D. Feldman/Heidrun Homburg, Industrie und Inflation. Studien und Dokumente zur Politik der deutschen Unternehmer 1916-1923, Hamburg 1977).

71 Reynaud, L'exécution. Den komplexen Vorgang der Instrumentalisierung der Inflation in der internationalen Reparationsdebatte durch die Regierung und verschiedene gesellschaftliche Gruppen in Deutschland beleuchtet ausführlich: Peter Krüger, Die Auswirkungen der Inflation auf die deutsche Außenpolitik, in: Gerald D. Feldman (Hg.), Die Nachwirkungen der Inflation auf die deutsche Geschichte 1924-1933 (Schriften des Historischen Kollegs, Kolloquien 6), München 1985, S. 297-314.

72 Reynaud, L'exécution.

73 Paul Reynaud, "L'Allemagne vaincue et les réparations (Notes de voyage)“, in: Journal de Barcelonnette, 1. 4. 1922. 
nötigenfalls jedem Alliierten die Sorge der Einigung mit Deutschland selbst zu überlassen. ${ }^{74}$

Um die Jahreswende 1921/22 konstatierte Reynaud deshalb ein weitgehendes Scheitern der französischen Reparationspolitik. Dabei unterschied sich seine Kritik an der Verminderung der deutschen Schuld und an ihrer gescheiterten Mobilisierung, an der verfehlten Einhandlung zusätzlicher Garantien und an der mißlungenen Regelung des interalliierten Schuldenproblems ${ }^{75}$ nicht wesentlich von den Vorwürfen, die in der Kammer von der gemäßigten Mitte bis zur nationalistischen Rechten gegen die Deutschlandpolitik Briands laut geworden waren. Zusammen mit wenigen anderen Repräsentanten der „modérés“ und in prinzipieller Übereinstimmung mit den Vorschlägen der sozialistischen Fraktion hatte er indes über die bloße Kritik hinausgehend ein tragfähiges Alternativkonzept auf die Ebene der parlamentarischen Diskussion gehoben, das zwar bereits in Expertenplänen ins Auge gefaßt worden war, doch erst mit den Vereinbarungen des Wiesbadener Abkommens ernsthaft Eingang in deutsch-französische Reparationsregelungen finden sollte. Gemäßigter als ein Briand der scharfen Töne, der nicht zuletzt mit Rücksicht auf die rechte Kammermehrheit im April 1921 die sofortige Ruhrbesetzung forderte, sah er in dieser Sanktion eine bei fortgesetzter deutscher Weigerung zwar denkbare, doch nur in allerletzter Konsequenz anzustrebende „solution du désespoir"76. Sachkundiger als ein verständigungsbereiter Briand faßte Reynaud das Wiesbadener Abkommen vom Oktober 1921 als hoffnungsvolles Zeichen für eine neue Haltung der Verantwortlichen in beiden Ländern auf, erkannte aber klar eine wesentliche Schwachstelle der Vereinbarungen. Das geplante System direkter Bestellungen der französischen Geschädigten in Deutschland mußte ja tatsächlich von vorneherein in Frage gestellt werden, solange der deutsche Staat nur unter Schwierigkeiten seinen Industriellen den Wert der gelieferten Waren in stabiler Währung bezahlen konnte und weiterhin in Gefahr stand, in Kürze bankrott zu gehen. ${ }^{77}$

In zweifacher Hinsicht erscheinen die Reynaudschen Vorschläge - über ihren Innovationsgehalt für die Regelung der internationalen Finanzbeziehungen hinausgehend - auch im Hinblick auf ihre Verankerung im innenpolitischen Kontext bemerkenswert. So muß das ostentativ bekundete Hinweggehen Reynauds über die Interessen der heimischen Industrie am Wiederaufbaugeschäft auf den ersten Blick erstaunen bei einem Abgeordneten, dessen politische Heimat für gewöhnlich in der Nähe der Geschäftswelt vermutet wird. Und in der Tat hatten die Publikationsorgane verschiedener Industriezweige, hatten Handelskammern, Arbeitgeberverbände und Einzelpersönlichkeiten aus der Wirtschaft keinen Zweifel an ihrer ablehnenden Haltung gegenüber Sachlieferungen gelassen oder zeigten sich allenfalls gewillt, solche Produkte zuzulassen, die die französische Industrie selbst nicht in ausreichender Menge bereitstellen konnte. ${ }^{78} \mathrm{Der}$ einflußreiche In-

74 Reynaud, L'exécution.

75 Vgl. etwa Reynaud, L'accord de Wiesbade.

76 Reynaud, L'exécution.

77 Reynaud, L'accord de Wiesbade.

78 Vgl. hierzu die Belege bei: Hermann Rupieper, The Cuno government and reparations 1922-1923. Politics and economics, Den Haag u.a. 1979, S. 8, Anm. 21; Jean-Noël Jeanneney, François de Wendel en République. L'argent et le pouvoir 1914-1940, Paris 1976, S. 128 f.; Weill-Raynal, Répa- 
dustrielle, Abgeordnete und Präsident des französischen Schwerindustriellenverbands „Comité des Forges“, François de Wendel, Vertreter einer harten Linie gegenüber Deutschland, gehörte ebenso wie sein Bruder Humbert zu den Meinungsführern einer Strömung in der französischen Wirtschaft, die sich aus „malthusianischer Furcht" vor deutscher Konkurrenz gegen die Durchführung der Wiesbadener Abmachungen wandte. ${ }^{79}$ Freilich war sein Einfluß zumindest auf parlamentarischer Ebene zu diesem Zeitpunkt noch begrenzt. In der Debatte um die Londoner Abmachungen vom Mai 1921 hatte er es nicht vermocht, seine Fraktionskollegen von der „Entente Républicaine Démocratique“ zur Enthaltung oder Opposition gegenüber Briands Deutschlandpolitik zu bewegen. ${ }^{80}$ Auch entzogen sich de Wendel in der Sachlieferungsfrage gerade jene Zirkel elsässischer Abgeordneter, in denen er für gewöhnlich auf den größten politischen Rückhalt zählen konnte: Immerhin befanden sich unter den 28 Unterzeichnern des von Reynaud in der Debatte vom 26. Mai vertretenen "Ordre du Jour" nicht weniger als 11 Abgeordnete Elsaß-Lothringens und der "régions dévastées“!81 Indes scheint man in Industriekreisen durchaus Zuflucht zu subtileren Methoden der Einflußnahme auf meinungsbildende Abgeordnete genommen zu haben. Zumindest im Falle Reynauds, der von einem französischen „Großindustriellen“, dessen Identität er verschweigt, um die Abkehr von seinen reparationspolitischen Vorstellungen angegangen worden war, blieben solche Versuche ergebnislos. ${ }^{82}$

Wesentlich größeres Gewicht im Kalkül Reynauds, der stets mit Gespür für Strömungen in der Bevölkerung agierte, hatte dagegen der offenkundige Widerwille weiter Teile der öffentlichen Meinung in Frankreich, deutsche Unternehmer und Arbeitskräfte in den Wiederaufbauregionen am Werk zu sehen - ein Gedanke, der in den deutschen Vorschlägen seit 1919 immer wieder aufgetaucht war. So hütete er sich in allen seinen Äußerungen zum Reparationsthema streng, den Einsatz deutscher Arbeiter befürwortend zu thematisieren. In der öffentlichen Diskussion, die sich um diese Frage im Verlauf des Jahres 1921 entzündet hatte, konnten sich dazu nahezu ausschließlich sozialistische Politiker und Gewerkschaftsvertreter durchringen. ${ }^{83}$ Dagegen paßte Reynaud seine Initiativen exakt dem Erwartungsprofil der Bevölkerung in den „régions dévastées“ an: Dort war man an einer Beschleunigung des schleppenden Wiederaufbaus interessiert, und

rations II, S. 59; Camille Didier, L'accord de Wiesbaden au point de vue de l'industrie et des sinistrés français, Paris 1921.

79 Jeanneney, de Wendel, S. 128.

80 Ebenda, S. 133.

81 Im einzelnen waren dies: Charles Frey (Bas-Rhin), Robert Schuman (Moselle), Charles Scheer (Haut-Rhin), Désiré Ferry (Meurthe-et-Moselle), Edouard de Warren (Meurthe-et-Mosellc), Georges Mazerand (Meurthe-et-Moselle), Robert Sérot (Moselle), Henri Philippoteaux (Ardennes), Charles Altorffer (Bas-Rhin), Camille Simonin (Bas-Rhin) und Eugène Muller (Bas-Rhin). Bezeichnend ist in diesem Zusammenhang, daß mit Sérot ein Abgeordneter unterzeichnete, der noch 1919 mit de Wendel auf einer gemeinsamen Liste kandidiert hatte. (JO, Chambre des Députes, Débats parlementaires, Séance du 26 mai 1921, S. 2417. Die Angaben zu den Abgeordneten sind entnommen aus: Jean Jolly $(\mathrm{Hg}$.), Dictionnaire des parlementaires français. Notices biographiques sur les ministres, députés et sénateurs français de 1889 à 1940, 8 Bände, Paris 19601977).

82 Reynaud, Mémoires I, S. 152-154.

83 Die Debatte um den Einsatz deutscher Arbeiter in den französischen Wiederaufbaugebieten resümiert: Ralph Schor, Les travailleurs allemands et la reconstruction de la France au lendemain de la Grande Guerre (1919-1923), in: Revue Historique 272 (1984), S. 113-130. 
stand, wie gesehen, über die Stimmen der eigenen parlamentarischen Vertreter einer Forcierung des Sachlieferungsprogramms offen gegenüber. ${ }^{84}$

Mit dem Sturz der Regierung Briand - bezeichnenderweise über die Reparationsproblematik - veränderten sich die innenpolitischen Bedingungen für die Formulierung der französischen Deutschland- und Reparationspolitik grundlegend. Der neue Ministerpräsident Poincaré hatte sich bereits 1919, damals noch Präsident der Republik, als Kritiker der Verhandlungsführung Clemenceaus und als Anhänger eines Sicherheitsfriedens hervorgetan, der garantierte deutsche Reparationszahlungen und insbesondere die fortdauernde Besetzung des Rheinlands bis zur vollständigen Erfüllung der deutschen Verpflichtungen einschließen sollte. Wenngleich aufgrund der verfassungsrechtlichen Grenzen seines Amtes und des politischen Gewichts des „Tigers“ seine diesbezüglichen Interventionen erfolglos blieben, galt Poincaré am Ende seines Septennats im Februar 1920 als einer derjenigen Staatsmänner, die sich während des vierjährigen Krieges größte Verdienste um Frankreich und ein entsprechend fundiertes Mitspracherecht in deutschlandpolitischen Belangen erworben hatten. Bis Januar 1922 lebte er in freiwilliger Enthaltsamkeit von allen Regierungsämtern. Vor allem als Mitglied des Senats und als Präsident seiner einflußreichen außenpolitischen Kommission schaffte er es in dieser Zeit, seine persönliche Niederlage erneut in hohe politische Autorität umzumünzen. Insbesondere erwarb er sich den Ruf eines engagierten Verfechters der Belange der zerstörten Regionen sowie der strikten Anwendung des Versailler Vertrags. ${ }^{85}$

Zwischen März 1920 und Januar 1922 nahm Poincaré regelmäßig in Le Matin, Le Temps und insbesondere in einer vierzehntägig erscheinenden politischen Chronik der Revue des Deux Mondes zu außen-, finanz- und vor allem reparationspolitischen Themen Stellung. ${ }^{86}$ Ausgehend von der Kritik am Versailler Vertrag und an dessen Urhebern zeichnete er hier ein pessimistisches Bild des deutsch-französischen Kräfteverhältnisses. Ein in seiner internationalen Bedeutung, seinem Selbstvertrauen und seiner finanziellen Leistungskraft geschwächtes Frankreich stand in Poincarés Darstellung einem revanchelüsternen Deutschland gegenüber, das die These seiner alleinigen Kriegsschuld leugne. Im Vertrauen auf englische Unterstützung setze man dort alles daran, um sich den für Frankreich überlebenswichtigen Reparationszahlungen durch eine verantwortungslose Aus-

${ }^{84}$ Zur Haltung der Bevölkerung, die wie die gesamte Wiederaufbauproblematik eine vertiefte Studie verdienen würde: Schor, Travailleurs, S. 116 und $129 \mathrm{f}$.

Ein im November 1921 auf Initiative der Gewerkschaft CGT organisiertes Referendum erbrachte in der Region von Chaulnes (Somme), die in Absprache mit der Regierung für einen ersten Versuch ausgewählt worden war, die Zustimmung von $84 \%$ der Bevölkerung. In einer zweiten Befragung, die auf Verlangen Loucheurs nur einen Monat später durch die Präfektur durchgeführt wurde, sprachen sich nach einer "Informationskampagne" der Regierung nurmehr $49 \%$ dafür aus (Schor, Travailleurs, S. 124-127; Weill-Raynal, Réparations II, S. 64-67).

85 Pierre Miquel, Poincaré, Paris 1961, S. 381-441.

86 Zur publizistischen Tätigkeit Poincarés zwischen 15.3. 1920 und 15.1. 1922: Georges Wormser, Le septennat de Poincaré, Paris 1977, S. 255-263.

Die Beiträge in der Revue des deux Mondes wurden bereits kurz nach ihrer ersten Veröffentlichung in vier Bänden gesammelt und neu herausgegeben: Raymond Poincaré, Histoire politique. Chroniques de quinzaine, 4 Bände, Paris 1920-22. 
gaben- und Inflationspolitik zu entziehen ${ }^{87}$ Bitter konstatierte er die englischen Pressionen, die darauf abzielen würden, das ohnehin bereits nach großen französischen Zugeständnissen zustandegekommene Versailler Vertragssystem einer grundlegenden Revision zu unterwerfen. ${ }^{88}$ Anders jedoch als Vertreter der nationalistischen Rechten wie Léon Daudet oder Maurice Barrès verfiel Poincaré keineswegs in die undifferenzierte Verdammung alles Deutschen. Er erkannte durchaus an, daß der wirtschaftliche Wiederaufstieg, ja Wohlstand der besiegten Nationen die unverzichtbare Vorbedingung für die Erholung Gesamteuropas sein würde und daß dazu auch die begrenzte wirtschaftliche Zusammenarbeit der ehemaligen Kriegsgegner ins Auge gefaßt werden müsse. ${ }^{89}$ Freilich aber implizierte sein Deutschlandbild das fortwährende Mißtrauen gegenüber einem östlichen Nachbarn, dessen „atavistische Eroberungsinstinkte“ 90 nur durch die Achtung vor französischer Stärke im Zaum gehalten werden könnten:

"Je veux bien admettre qu'il ne soit pas nécessaire de nous faire craindre par l'Allemagne; mais, dans l'intérêt même de nos relations futures, il est, à tout le moins, indispensable qu'elle nous respecte et qu'elle nous estime; et, si elle nous sent faibles, nous ne serons jamais à ses yeux qu'un peuple inférieur. Que la France soit à même de traiter avec elle d'égale à égale, c'est la meilleure façon de préparer, pour l'avenir, un rapprochement sincère entre les deux nations. “91

Gab Poincaré sich zunächst in der Kritik an den Regierungen des „Bloc national" noch zurückhaltend, so ging er mit Machtantritt Briands offen auf Oppositionskurs. Eine breite rechte Strömung in der Kammer, die dem außenpolitischen Handeln des Ministerpräsidenten gegenüber Deutschland, in der Orient- und in der Abrüstungsfrage ab Herbst 1921 zunehmend kritisch gegenüberstand, nahm ihn daraufhin immer dringender als möglichen Nachfolger in den Blick. ${ }^{92}$ Dies geschah in dem Maße, in dem klar wurde, daß Briand in bezug auf die zwei Alternativen, welche bisher in seiner Deutschlandpolitik in unterschiedlicher Gewichtung zum Tragen gekommen waren, allmählich eine deutliche Präferenz entwikkelte: $Z$ wischen der harten $Z$ wangs- und Sanktionspolitik einerseits und dem Versuch einer pragmatischeren Lösung „im Vertrauen auf das demokratische Deutschland " 93 und unter Berücksichtigung der englischen Interessen andererseits, neigte der Ministerpräsident zunehmend der zweiten Option zu. Der Mitverantwortliche für das Ultimatum an Deutschland im Februar 1921, für den Einmarsch in mehrere rechtsrheinische Orte im folgenden Monat und für eine konse-

87 Miquel, Poincaré, S. 420-428. Zum Revanchevorwurf: Poincaré, Histoire politique I, S. 272 (1. 9. 1920). Zu seiner Kritik an der Ausgabenpolitik des deutschen Reiches: Ebenda II, S. 207-216 (15.1.1921).

88 Vgl. u.a. Ebenda I, S. 77 f. (1. 5. 1920), S. $127 f$ (1.6. 1920), S. 88-92 (1. 5. 1920), S. 113 f. (15. 5. 1920).

89 Ebenda I, S. 48 (1. 4. 1920) und S. 119 (15. 5. 1920). Als rücksichtsloser Vertreter einer Gewaltpolitik gegenüber Deutschland und "Anwalt eines schrankenlosen Nationalegoismus" erscheint Poincaré als Verfasser der "Chroniques de quinzaine" einseitig dargestellt bei Norbert Ohler, Deutschland und die deutsche Frage in der „Revue des deux Mondes" 1905-1940. Ein Beitrag zur Erhellung des französischen Deutschlandbildes, Frankfurt 1973, S. 142-164 passim (Zitat S. 157).

90 Ebenda I, S. $63(15.4$. 1920) und ebenda II, S. 191 (1.1.1921).

91 Ebenda II, S. 192 (1.1.1921).

92 Miquel, Poincaré, S. 428f; Bonnefous, Histoire III, S. 261-282.

93 So Briand in seiner Stellungnahme vor dem Senat (Bonnefous, Histoire III, S. 266). 
quente Oberschlesienpolitik zum Nutzen Frankreichs hatte sich nicht nur ab Frühsommer 1921 auf bilaterale deutsch-französische Gespräche eingelassen oder im September zur Aufhebung der wirtschaftlichen Sanktionen gegen die besetzten rheinischen Gebiete bereitgefunden. Mit seinem Eingehen auf Verhandlungen über den englischen Vorschlag eines Tauschgeschäfts britischer Sicherheitsgarantien für Frankreich gegen die Neuverhandlung des Londoner Zahlungsplans hatte er sich endgültig auf den Weg der reparationspolitischen Revision des Versailler Vertrags begeben. ${ }^{94}$

Paul Reynaud hatte die Entwicklung des siebten Kabinetts Briand nicht ohne Sympathie verfolgt. Weniger jedoch die Nähe zur politischen Persönlichkeit des Ministerpräsidenten war es, die ihn über weite Strecken des Jahres 1921 hin zur kritischen Loyalität veranlaßt hatte, sondern vielmehr die Hoffnung auf entschiedenere Umsetzung einer Deutschlandpolitik, für die er in der zweiten Jahreshälfte verheißungsvolle Ansätze hatte konstatieren können. Wenngleich er nie die Skepsis verlor gegenüber einem Briand, der die ausgeprägte Fähigkeit besaß, feindselige parlamentarische Stimmungen aufzufangen und so gedeckt auf internationaler Ebene in beunruhigendem Maße eigene Wege zu gehen, zeigte sich Reynaud nicht unzugänglich gegenüber der sachlichen Notwendigkeit von Zugeständnissen in der Reparationsfrage. Bis zuletzt jedoch bemängelte er die Konzeptionslosigkeit der Regierung Briand in dieser Hinsicht, auf die er das Scheitern der vielversprechenden Ansätze von Wiesbaden zurückführte. ${ }^{95}$

Dem im Hintergrund gegen Briand wirkenden Poincaré hatte Reynaud einen Vertrauensvorschuß entgegengebracht, der in erster Linie der Person galt und dem, was sie verkörperte. In der Tat bot Poincaré in seiner Regierungserklärung vom 19. Januar kaum neue deutschlandpolitische Inhalte. Sein Bekenntnis zum Versailler Vertrag und zur Aufrechterhaltung der Allianzen mit dessen Garantiemächten stellte eher eine unspektakuläre, „akademisch“ eingefärbte Pflichtübung dar. ${ }^{96}$ Ungeachtet dessen rückte Reynaud aufatmend den vielversprechenden "neuen Geist" in den Vordergrund, der mit dem Amtsantritt des Regierungschefs in die Deutschlandpolitik Frankreichs Einzug gehalten habe:

„Par son langage, par son attitude, par sa voix mordante et nette, par l'autorité qui émane de sa personne et de ses anciennes fonctions, M. Poincaré a ranimé tout d'abord la fierté de la victoire oubliée." 97

Das Potential der "neuen Politik“ Poincarés erschöpfte sich in seinen Augen nicht in kompromißloser Härte: Er erwartete zustimmend eine energischere, effektivere Nutzung der im Versailler Vertrag angelegten Möglichkeiten einschließlich der Anwendung direkter Sanktionsdrohung gegen Deutschland, doch traute er ihr auch die entscheidende Nuance zu, die seiner Meinung nach daneben nicht fehlen durfte:

„Mais ce n'est là que l'une des deux branches de la politique que nous devons adopter à l'égard de l'Allemagne. Il faut menacer d'une main, mais il faut offrir de

94 Vgl. Becker/Berstein, Victoire et frustrations, S. 212-214.

95 Paul Reynaud, „Vers le Redressement de la Politique Française?“, in: Journal de Barcelonnette, 1. 2. 1922.

96 Bonnefous, Histoire III, S. $284 \mathrm{f}$.

97 Reynaud, Redressement. 
l'autre. Gardons-nous surtout de montrer à l'Allemagne, dont le désarroi moral est profond, un avenir sans espoir." "Denn: „La vérité est que le peuple allemand, qui a plus souffert qu'aucun autre pendant la guerre, parce qu'il a vécu en vase clos, alors que nous étions ravitaillés par le monde entier, a subi le poids d'une révolution économique qui est venu doubler l'effondrement moral de la défaite."99

Einmal mehr ergriff Reynaud den Anlaß, die Elemente seines deutschlandpolitischen Credos vorzutragen. Das Eingehen auch auf die Bedürfnislage der Gegenseite, das Einbetten des Reparationsproblems in den gesamteuropäischen Rahmen und die Erarbeitung eines Wiedergutmachungsplans, der der Tatsache Rechnung zu tragen habe, daß Deutschland seine Verpflichtungen aus dem Londoner Zahlungsplan nicht in bar werde erfüllen können, stellten für ihn unabdingbare Konstanten eines „gemäßigten“ Konzepts dar. 100

$\mathrm{Ob}$ ihm freilich verborgen geblieben war, daß Poincarés Bereitschaft zu entgegenkommendem Vertrauen in die Leistungsbereitschaft der deutschen Seite deutlich geringer ausgeprägt war als die eigene, muß bezweifelt werden. Einem aufmerksamen Leser der "Chroniques de quinzaine“ konnte nicht entgangen sein, daß die These vom „betrügerischen Bankrott" des deutschen Staates, die er, Reynaud, so fundiert und beredt zu relativieren versucht hatte, ein Kernstück der Poincaré'schen Doktrin bildete. ${ }^{101} \mathrm{Daß}$ der neue Ministerpräsident überdies deutsche Sach- und Arbeitsleistungen als Teil eines Täuschungsmanövers zum Schaden der französischen Industrie verstand und nur als „außergewöhnlichen“ und „übergangsweisen " Zahlungsmodus zu akzeptieren bereit war, hatte er bereits seit langem wiederholt klargemacht. ${ }^{102}$ So entsprang es wohl nicht nur rein volkswirtschaftlichen Überlegungen, als Reynaud im Frühjahr 1922 sein reparationspolitisches Konzept in einem entscheidenden Punkt modifizierte.

\section{b) Regelung der Reparationsfrage durch Aktienbeteiligungen an der deutschen Industrie?}

Mitte März 1922, knapp zwei Monate nach Regierungsantritt Poincarés, legte Reynaud in der konservativen Tageszeitung Le Matin einen neuen Plan vor, der versuchte, der veränderten internationalen Lage Rechnung zu tragen und gleichermaßen außenwirtschaftliche, psychologische, reparations- und sicherheitspolitische Aspekte berücksichtigte. Inspiriert durch das System deutscher Kontributionsentnahmen aus den besetzten Gebieten Nordostfrankreichs während des Ersten Weltkriegs und in bewußter Anknüpfung an Vorschläge des deutschen Wirtschaftsexperten Julius Hirsch, sah sein Konzept die Aufstockung des Kapitals

\footnotetext{
${ }^{98}$ Ebenda.

99 Reynaud, L'Allemagne vaincue et les réparations.

100 Reynaud, Redressement.

101 Anhand einer ausführlichen Analyse des deutschen Budgets für das Jahr 1921 versuchte Poincaré etwa zu demonstrieren, daß überflüssige Ausgaben eingespart und zusätzliche Einnahmequellen erschlossen werden könnten (Poincaré, Histoire politique II, S. 207-217). Zum Bild von der rasch wiedererstehenden deutschen Industrie auch: Ebenda, S. 237-240 (1.2. 1921).

Der Gedanke findet sich auch in seiner Regierungserklärung vom 19. Januar 1922: JO, Chambre des Députés, Débats parlementaires, Séance du 19 janvier 1922, S. 37 f., hier: S. 38.

102 Ebenda I, S. 63-65 (15. 4. 1920); ebenda, S. 117-120 (15. 5. 1920); ebenda II, S. 216f. (15. 1. 1921). Dazu auch Trachtenberg, Reparations, S. 238.
} 
deutscher Aktiengesellschaften um ein Fünftel ihres Wertes und die Hypothekenbelastung des gesamten Immobilienbesitzes im gleichen Ausmaß jeweils zugunsten der Übereignung dieser Anteile an die Reparationskommission vor. In logischer Fortentwicklung dieses Verflechtungsansatzes sollten über deutsch-französische Handelsverträge, über die Zusammenarbeit im Bereich des Bergbaus und des Hüttenwesens gemeinsam Preisvorteile erreicht und neue Märkte etwa in Rußland erschlossen werden. Daß Reynauds Überlegungen ganz konkrete wirtschaftliche Ziele zugrundelagen wie die Sicherung von Absatzmärkten für die französische Industrie und die wirksame Kontrolle der günstiger produzierenden deutschen Konkurrenz, gab er offen zu. Fernziel blieb jedoch die politische Annäherung auf der Basis der "moralischen Abrüstung" und inneren Stabilisierung Deutschlands, die sich in Verträgen zur Garantie der gegenseitigen Grenzen und in der Verminderung der französischen Besatzungstruppen im Nachbarland niederschlagen sollte. ${ }^{103}$

Neu war auch diese Lösung der Übernahme von Anteilen am deutschen Kapital- und Produktionsvermögen zu Reparationszwecken nicht. Seitens der deutschen Regierung waren bereits im Umfeld der Friedensverhandlungen zwischen dem Waffenstillstand vom November 1918 und der Unterzeichnung des Versailler Vertrags Ende Juni 1919 Pläne für eine alliierte Beteiligung an deutschen Industrieunternehmen aufgegriffen worden. Sie gingen zurück auf den deutschen Industriellen Arnold Rechberg, der sie zunächst mit Blick auf eine wirtschaftliche Annäherung an den englischen Kriegsgegner seit Januar 1918 wiederholt in Kreisen der Industrie und des Auswärtigen Amts vorgetragen hatte. Kurzzeitig deutete sich so im Frühjahr 1919 die Möglichkeit einer deutsch-französischen industriellen Zusammenarbeit unter antienglischem Vorzeichen an: Tatsächlich fanden die deutschen Vorschläge an die Alliierten, die im Mai 1919 mit Billigung der Industrie darauf abzielten, durch die Preisgabe von Anteilen deutscher Kohlenzechen an französische Unternehmen die drohende Abtrennung deutscher Industriegebiete zu vermeiden, zunächst ermunternde Aufnahme seitens der französischen Unterhändler. Erst aufgrund des Meinungsumschwungs der Delegierten Frankreichs, der vermutlich mit Rücksicht auf Großbritannien erfolgte, blieben sie dann doch nur Episode. ${ }^{104}$

Waren die deutschen Angebote vom Mai 1919 in erster Linie entstanden, um unter Zugzwang in der Reparationsfrage Schlimmeres zu verhüten, ohne daß bereits umfassendere Vorstellungen für interne Regelungen zwischen der Reichsregierung und der Industrie entwickelt worden waren ${ }^{105}$, so änderte sich das, als das Konzept im Mai 1921 durch den Staatssekretär im Reichswirtschaftsministerium, Julius Hirsch, erneut aufgenommen wurde. Den Anlaß für den Rückgriff auf die Option der Kapitalbeteiligung bildete diesmal die Annahme des Londoner Ultimatums durch die Regierung Wirth. Ergab sich doch daraus die Notwendigkeit, angesichts der maroden Staatsfinanzen langfristig wirksame Alternativen zur

103 Paul Reynaud, „Un moyen d'éviter un désastre européen. Affecter aux réparations une partic du capital du Reich“, in: Le Matin, 14. 3. 1922.

104 Vgl. hierzu Krüger, Deutschland und die Reparationen 1918/19, S. 174-181; Wulf, Stinnes, S. 177179.

105 Krüger, Deutschland und die Reparationen 1918/19, S. 180. 
Finanzierung deutscher Reparationsleistungen über die Erhöhung des Steueraufkommens zu finden, welche sich in der Vergangenheit bereits als nicht hinreichend effektiv erwiesen hatte. Kern des Konzepts über die „Belastung der Sachwerte als Teil des Reparationsprogramms“ war der Gedanke, zur Deckung des defizitären Etats und der Reparationsschuld anstelle der bisher weitgehend betroffenen Kapitaleigner nun verstärkt die Besitzer von Sachwerten und Produktionsmitteln heranzuziehen. ${ }^{106}$ Dazu schlug Hirsch die Belastung des landwirtschaftlichen Grund- und städtischen Wohnbesitzes durch eine zwanzigprozentige Hypothek sowie die Übernahme von Anteilen in gleicher Höhe an allen Industrie- und Handelsunternehmen jeweils zugunsten des deutschen Staates vor. Diesem sollten im Ergebnis nicht nur die entsprechenden Sach- und Jahreserträge zugute kommen, sondern darüber hinaus verstärkt In- und Auslandskredite zufließen, denen die belasteten Werte als Sicherheiten dienen würden. ${ }^{107}$ Ziel war also letztlich, durch die Deckung des deutschen Haushaltsdefizits über die „Mobilisierung von Substanzwerten " den weiteren inflationären Verfall der deutschen Währung zu bremsen und so ihre Kreditwürdigkeit im Ausland zu stärken; mit der Erfüllung einer regelmäßig vorgebrachten alliierten Forderung hoffte man zudem, „unorganische Eingriff[e]“ der Entente in den deutschen Staatshaushalt zu vermeiden. ${ }^{108}$

Die Widerstände gegen den von der SPD gestützten und stark innenpolitisch motivierten Vorschlag aus dem Reichswirtschaftsministerium warfen ein bezeichnendes Licht auf die Stimmungslage, auf die das Konzept Reynauds in Deutschland treffen mußte. Entgegen der Annahme seiner konservativen Kritiker zielte Hirsch zwar keineswegs auf eine verdeckte Sozialisierung der deutschen Wirtschaft; viel eher erstrebte er ihre „kontrollierte Liberalisierung“ zur Förderung von Rationalisierung und Konkurrenzfähigkeit. ${ }^{109} \mathrm{Er}$ scheiterte gleichwohl an der Unentschlossenheit Reichskanzler Wirths, der entgegen anderslautender öffentlicher Äußerungen den Plan angesichts der schwankenden Basis seiner Regierung politisch nicht für durchsetzbar hielt. Ausschlaggebend waren zudem Widerstände in den konservativen Parteien und im Reichsfinanzministerium, in denen sich im Kern Vorbehalte gegen das Konzept der Erfüllungspolitik insgesamt manifestierten. Insbesondere der Staatssekretär im Reichsfinanzministerium, Heinrich Zapf, wandte sich gegen den Versuch, durch ein so weitgehendes Programm die anzustrebende Einsicht der Alliierten in die deutsche Zahlungsunfähigkeit hinauszuzögern oder gar zu verhindern. Er fürchtete zudem - und dieses Sorge wurde von Kabinettsmitgliedern wie Wiederaufbauminister Rathenau geteilt -, den Kontrollinstitutionen der Entente ein nur allzu probates Mittel an die Hand

106 Der Plan wurde am 19. Mai 1921 im Kabinett diskutiert und bis 27. Juni zu einer Denkschrift ausgebaut. Die Schrift findet sich in ihrer Erstfassung abgedruckt in: Die Kabinette Wirth I und II. 10. Mai 1921 bis 26. Oktober 1921. 26. Oktober 1921 bis 22. November 1922. Band I, bearb. von Ingrid Schulze-Bidlingmaier, Boppard 1973, S. 7-13. Die erweiterte Form bei: Julius Hirsch, Die deutsche Währungsfrage (Kieler Vorträge 9), Jena 1924, S. 58-69.

Allgemein zu den Vorschlägen Hirschs: Feldman, Great Disorder, S. 350-354. Zur Vorgeschichte auch: Wulf, Stinnes, S. 266-268.

107 Hirsch, Währungsfrage, S. 60-65.

108 Ebenda, S. 67 f.; Zitate: S. 68.

109 Feldman, Great Disorder, S. 351. 
zu geben, um unerwünschten Einfluß auf die von staatlicher Hand gehaltenen Anteile und damit auf die deutsche Wirtschaft zu nehmen. Angesichts dieser vereinten Gegnerschaft verliefen die Bemühungen Hirschs bis Herbst 1921 endgültig im Sande. Kabinett und Finanzministerium blieben zur Haushaltskonsolidierung weiterhin auf das traditionelle Mittel der Steuergesetzgebung verwiesen. ${ }^{110}$ Auf reparationstechnischem Gebiet bildete im Sommer 1921 die Sachlieferungsoption für die Reichsregierung nach wie vor die wichtigere Alternative, um das schier unlösbar erscheinende Transferproblem zumindest teilweise zu entschärfen."11

Die Grenzen dieses im Wiesbadener Abkommen festgeschriebenen Ansatzes waren indes bis Jahresbeginn 1922 deutlich geworden und hatten Reynaud laut eigenem Bekunden zur Änderung seiner Haltung bewogen. Er hielt nun die Sachlieferungslösung aufgrund neuer, ungünstiger Rahmenbedingungen für zunehmend undurchführbar und erachtete sie in deutlicher Annäherung an die Position Poincarés nurmehr als Zusatzoption für akzeptabel: Sah er doch, daß der in der zweiten Jahreshälfte 1921 einsetzende rapide Markverfall und die verfehlte Konsolidierung des deutschen Staatshaushalts dem vorgesehenen System staatlicher Ausgleichszahlungen an deutsche Industrielle extrem abträglich sein würden. ${ }^{112}$

Es muß erstaunen, daß damit das System der Sachlieferungen einen seiner engagiertesten Befürworter in Frankreich zu einem Zeitpunkt verlor, als diese Option noch bei weitem nicht an die Grenzen ihrer Ausbaumöglichkeiten gestoßen war. Immerhin sah das Jahr 1922 mit dem Cuntze-Bemelmans-Abkommen, den Gillet-Ruppel-Vereinbarungen und dem Stinnes-Lubersac-Abkommen eine Folge von teils staatlichen, teils zwischen Industrievertretern geschlossenen Sachlieferungsverträgen, die die Schwächen der Wiesbadener Bestimmungen teils erfolgreich ausglichen. ${ }^{113}$ Freilich hatten die Vereinbarungen bis dato vor allem wegen des Widerstandes der Schwerindustrien beider Länder, aufgrund widerstreitender handelspolitischer Interessen der deutschen und der französischen Seite sowie der Vorbehalte der Alliierten Frankreichs nicht die erhofften Ergebnisse gebracht.114 Auch konnte Reynaud davon ausgehen, daß sein neuer Vorschlag in Kreisen der Industrie auf zumindest vereinzelte Sympathien stoßen würde. ${ }^{115}$ Mit ausschlaggebend für die Hartnäckigkeit, mit der er über Jahre hinweg an der Idee der Indu-

110 Ebenda, S. 352-354. Zu den Argumenten Zapfs: Kabinette Wirth I und II, Band I, S. 6 f. (Chefbesprechung vom 19. 5. 1921), zur Haltung Rathenaus: Ebenda, S. 118 (Kabinettssitzung vom 29. 6. 1921).

111 Feldman, Great Disorder, S. 356.

112 Reynaud, Un moyen d'éviter un désastre européen; Ders., L'Allemagne vaincue et les réparations.

113 Zu den genannten Vereinbarungen im Überblick: Wulf, Stinnes, S. 324-329.

114 Zur Kritik der deutschen Schwerindustrie am Wiesbadener Abkommen vgl. Wulf, Stinnes, S. 320324 sowie Feldman, Great Disorder, S. 356-358; die ablehnende Haltung der französischen Industrie findet sich erläutert bei Jeanneney, de Wendel, S. 127-130. Dazu auch Wurm, Frankreich, die Reparationen und die interalliierten Schulden in den 20er Jahren, in: Feldman, Nachwirkungen, S. 321 sowie Krüger, Außenpolitik, S. 146f. Zu den Widerständen allgemein: Weill-Raynal, Réparations II, S. 52-67.

115 So hatte etwa Henry de Peyerimhoff, Generalsekretär der französischen Grubenvereinigung „Comité des Houillères" öffentlich vorsichtige Zustimmung bekundet. François de Wendel stand allerdings auch diesem Konzept Reynauds ablehnend gegenüber und übte auf das Direktorium des "Comité des Forges“ im Frühjahr 1922 entsprechenden Einfluß aus (Jeanneney, de Wendel, S. $152 \mathrm{f}$.). 
striebeteiligungen festhielt und diese noch im Jahr 1929 erneut politisch nutzbar zu machen versuchte, dürfte indes die Tatsache geworden sein, daß ihm durch die Bekanntschaft mit Arnold Rechberg ein deutscher Verbündeter für die Verteidigung seiner Idee erwachsen war.

Der wohlhabende Industrielle und politische Schriftsteller Rechberg hatte bereits vor dem Ersten Weltkrieg versucht, als dilettierender Privatmann Einfluß auf den Gang der deutsch-französischen Beziehungen zu nehmen. Seit 1904 in Paris ansässig, war er mit Ausbruch des Ersten Weltkriegs nach Deutschland zurückgekehrt und pflegte dort Beziehungen u.a. zu Matthias Erzberger, nach Kriegsende auch zur nationalistischen Rechten sowie zu Vertretern der Entente. Daneben entfaltete er eine umfangreiche publizistische Tätigkeit in der deutschen, englischen und französischen Presse, wo er seit 1920 Pläne für eine antibolschewistische Koalition Westeuropas entwickelte. In diesem Zusammenhang hatte er neben Militärprojekten insbesondere die Idee der europäischen Wirtschaftsverflechtung über alliierte Aktienbeteiligungen an der deutschen Industrie in die Diskussion gebracht. 116

Einer der französischen Gesprächspartner Rechbergs, der Leiter der „ständigen Delegation des Garantiekomitees der Reparationskommission in Berlin “, Emile Haguenin 117, war auf den Artikel Reynauds in Le Matin vom März 1922 aufmerksam geworden. Er bahnte daraufhin den Kontakt an und informierte Reynaud ausführlich über die Pläne Rechbergs. ${ }^{118}$ Auf Einladung des deutschen Industriellen kam es so im Oktober 1922 zu einem ersten Treffen in Berlin. Hier vermittelte Rechberg seinem Gast unter anderem ein Treffen mit General Ludendorff, den er seit Kriegsende für seine Vorstellungen einer Zusammenarbeit mit Frankreich unter antisowjetischem Vorzeichen zu gewinnen suchte. ${ }^{119}$ Das Gespräch, in dem Ludendorff offensichtlich Interesse an Reynauds Reparationsidee zeigte und seine Zustimmung zu einer gütlichen Lösung hinsichtlich Elsaß-Lothringens andeutete ${ }^{120}$, bestärkte Reynaud in seinen Ansichten und ließ ihn, mit neuen Argumenten versehen, nach seiner Rückkehr erneut verstärkt deutschlandpolitisch aktiv werden.

116 Vgl. Eberhard von Vietsch, Arnold Rechberg und das Problem der politischen West-Orientierung Deutschlands nach dem 1. Weltkrieg, Koblenz 1958; Werner Bührer, Rechberg, Arnold, in: Wolfgang Benz/Hermann Graml (Hg.), Biographisches Lexikon zur Weimarer Republik, München 1988 , S. $265 \mathrm{f}$

117 Zur Person Emile Haguenins vgl. Henning Köhler, Novemberrevolution und Frankreich. Die französische Deutschlandpolitik 1918-1919, Düsseldorf 1980, passim sowie Stefan Martens, Einleitung, in: Ders. (Hg.), Documents Diplomatiques Français sur l'Allemagne 1920. Französische Diplomatenberichte aus Deutschland 1920, Band 1 (Pariser Historische Studien 33/1), Bonn/Berlin 1992, S. 29-149, hier: S. 44-55.

118 Vgl. das Schreiben Rechbergs an Reynaud vom 21.3.1922 (AN, 74 AP 11) sowie die Note Haguenins "Les idées de $\mathrm{M}$. Rechberg sur le problème des réparations et la reconstitution économique“ vom 13.4. 1922 (ebenda), in der dieser vorab die Thesen einer angekündigten Buchveröffentlichung Rechbergs analysierte. Die Arbeit erschien schließlich unter dem Titel: Arnold Rechberg, Was kostet der Friedensvertrag die Entente?, München 1922.

Von Vietsch, der Reynaud irrtümlich verwandtschaftliche Beziehungen zur Industriellenfamilie Schneider-Creusot unterstellt, setzt die Kontaktaufnahme beider Männer fälschlicherweise erst für den Herbst 1922 an (von Vietsch, Rechberg, S. 85 f.).

119 Zum vielschichtigen Verhältnis Rechbergs zu Ludendorff: von Vietsch, Rechberg, S. 65-73.

120 Über die halbstündige Unterredung mit dem General gibt Reynaud Aufschluß in einer Gesprächsnotiz vom 9. 10. 1922 (AN, 74 AP 11). 
Bereits im Mai hatte Reynaud keinen Hehl aus seiner Ansicht gemacht, daß das faktische Scheitern der Konferenz von Genua nicht zuletzt als Folge der traditionellen englischen Kontinentalpolitik interpretiert werden müsse, die nicht umhin könne, die Isolierung der Industriemacht Frankreich anzustreben. In Deutschland dagegen könnten selbst nationalistische Zirkel nicht an der Einsicht vorbei, daß die Entwicklung des eigenen Industriepotentials der Isolierung des französischen Nachbarn entgegenstehe. ${ }^{121}$ Diese richtig beobachtete Interessenskollision lag in der Tat den vielfältigen Ansätzen zu deutsch-französischen Industrieverhandlungen zugrunde, die sich im Herbst 1922 auf Initiative beider Seiten ergaben. ${ }^{122}$ Mit großem Nachdruck griff Reynaud deshalb das Stichwort auf, das ihm Ludendorff gegeben hatte, und präsentierte die versöhnlichen Äußerungen des Weltkriegsgenerals als weiteren Beleg für das „natürliche“ Interesse auch konservativer deutscher Kreise am Ausgleich - ein Interesse, das er in diesem Falle auf die in seinen Augen berechtigte Sorge vor bolschewistischen Unruhen zurückführte. ${ }^{123}$

In einer großen und von den Abgeordneten mit Aufmerksamkeit zur Kenntnis genommenen Parlamentsrede faßte Reynaud am 20. Oktober 1922 seinen Standpunkt zusammen. Er verwies auf den weitgehenden Verfall der Autorität eines aus der "Scham der Niederlage“ geborenen deutschen Staates und auf die allgemeine Zerrüttung seines Wirtschaftslebens. Und er vertrat zum wiederholten Male die Aussichtslosigkeit des Unterfangens, durch immer neue Kontroll- und Zwangsmaßnahmen deutsche Zahlungen zu erreichen. Die Idee der Industriebeteiligungen stellte er unter expliziter Berufung auf die Alternativvorschläge Arnold Rechbergs und Julius Hirschs in den Mittelpunkt seiner Ausführungen. Ohne eine Besetzung der Ruhr definitiv auszuschließen, übte er außerdem heftige Kritik an der Politik regelmäßig wiederholter ineffektiver Drohungen Poincarés, die ebensowenig wie diejenige seines Vorgängers zu einem geschlossenen, der Weltöffentlichkeit vermittelbaren und erfolgreichen Reparationsprogramm geführt hätte: „[...] le monde, et la France en particulier, sont fatigués par le rythme des conférences précédées de discours menaçants et suivies de discours désabusés. [...] Messieurs, s'il est vrai que l'Allemagne est telle que je l'ai comprise et que je la dépeins, il ne faut pas essayer de s'adresser à l'Etat allemand. J'entends bien que c'est avec lui que nous négocions. Mais ce n'est pas lui qu'on pourra faire payer. Ce n'est pas par l'impôt prélevé sur la masse que nous pourrons être payés. [...] La richesse allemande a quitté la masse, elle est montée vers quelques puissants seigneurs: c'est à eux qu'il faut s'adresser. [...]“ ${ }^{124}$ Und unter Verwendung eines Zitats aus dem Vorwärts ergänzte er: „,[...] Il ne manque certainement pas, en Allemagne, de gens

121 Paul Reynaud, „Et maintenant, quelle politique?“, in: Revue Hebdomadaire, 27. 5. 1922; wieder abgedruckt in: Journal de Barcelonnette, 10. 6. 1922.

122 Vgl. das Resümee dieser Gespräche bei Wulf, Stinnes, S. 329-343.

123 "Ce qu'a dit le Général Ludendorff à M. Paul Reynaud“, in: Journal de Barcelonnette, 31. 10. 1922. $\mathrm{Zu}$ Reynauds Besorgnis vor bolschewistischen Unruhen in Deutschland angesichts der prekären Wirtschaftslage siehe seine Pressenotizen über seinen Deutschlandbesuch (AN, 74 AP 11, Dossier: "Voyage à Berlin, octobre 1922. Notes pour journaux").

${ }_{124}$ JO, Chambre des Députés, Débats parlementaires, Séance du 20 octobre 1922, S. 2756-2765 (Zitate: S. 2756 und 2760. Vgl. auch Bonnefous, Histoire III, S. 335-337. Bariéty datiert die Rede Reynauds irrtümlicherweise auf den 12.10. und geht nicht auf dessen Reparationsvorschlag ein. So entsteht der unzutreffende Eindruck, Reynaud habe alternativelos die Ruhrbesetzung empfohlen (Bariéty, Relations, S. 106). 
capables de payer, mais leur patriotisme aurait fort besoin d'être aidé par un huissier impartial.' Monsieur le président du conseil, cet huissier impartial, dont nous regrettons tant et si cruellement l'absence à la Société des nations (Très bien! très bien!), à défaut de mieux, ce pourrait être vous. Car pour cela, oui, l'action, d'accord avec une fraction de l'opinion publique allemande, pour cela, oui, même la Ruhr, quand il s'agit d'imposer une solution définitive au problème; mais pas la Ruhr tous les deux mois, pour obtenir quelques millions. [...] Je demande à la Chambre la permission de croire que, entre la politique de l'autruche et la politique du taureau, il peut y avoir une troisième politique qui soit une politique de réalisations; c'est celle-là que je viens proposer à la Chambre." 125

Im Unterschied zu zwei anderen, seit Mai 1922 in Regierungskreisen kursierenden Plänen, die wie Reynauds Konzept die Übernahme französischer Kontrolle über deutsches Industriekapital vorsahen, empfahl Reynaud weder die Ruhrbesetzung als vorrangiges Ziel noch eine darauf aufbauende separatistische Rheinlandpolitik. Er verstand eine Besetzung der Ruhr vielmehr als letztes und stärkstes Druckmittel, um die deutsche Industrie zur Annahme einer Partizipationslösung zu bringen, die letztlich auf das ganze Reichsgebiet Anwendung finden sollte.126 Dabei bestand zum Zeitpunkt seiner Intervention durchaus noch Anlaß zur Hoffnung, die offizielle Haltung Frankreichs in dieser Frage zu beeinflussen. Zwar hatte Poincaré eine "politique des gages“ mit Besetzung der Ruhr seit Juni als mögliche Lösung ins Auge gefaßt; seine endgültige Entscheidung fällte der Regierungschef jedoch erst Mitte November. Bis dahin warben widerstreitende Tendenzen um seine Unterstützung, getragen vor allem von hohen Beamten in den besetzten rheinischen Gebieten auf der einen, von Finanzminister de Lasteyrie auf der anderen Seite. ${ }^{127}$ Der Moment war mithin gut gewählt, um Gehör zu finden.

Poincaré hielt die Vorschläge Reynauds für immerhin so wichtig, daß er darauf in einer ausführlichen, ablehnenden Replik im Rahmen einer Kammerrede einging, in der sein Mißtrauen gegenüber den deutschen Urhebern des Plans zum Ausdruck kam. Der vermutliche geringe Ertrag der vorgeschlagenen Lösung und praktische Ausführungsprobleme standen im Mittelpunkt seiner Erklärungen, die das vorläufige Aus für alle Hoffnungen auf eine mögliche rasche Umsetzung des „Rechberg-Reynaud-Plans“ bedeuteten und von der Kammer ohne erkennbaren Widerstand aufgenommen wurden. ${ }^{128}$ Mehr noch als die angeführten Gründe, deren Stichhaltigkeit mit Recht bezweifelt werden konnte ${ }^{129}$ war wohl für Poincarés

125 JO, Chambre des Députés, Débats parlementaires, Séance du 20 octobre 1922, S. 2761.

$126 \mathrm{Zu}$ den Plänen des Oberkommandierenden der Rheinarmee, Degoutte, sowie den vermutlich durch Tirard inspirierten Vorschlägen des Abgeordneten Dariac vom 2. bzw. 28. Mai 1922 vgl. Bariéty, Relations, S. 96-101; Ludwig Zimmermann, Frankreichs Ruhrpolitik von Versailles bis zum Dawesplan, Göttingen 1971, S. 78-81. Bariéty betont die Parallelitäten zwischen den Entwürfen Degouttes, Dariacs und Reynauds (Bariéty, Relations, S. 106).

127 Vgl. Bariéty, Relations, S. 97 bzw. 101-108.

128 JO, Chambre des Députés, Débats parlementaires, Séance du 17 novembre 1922, S. 3241-3248, hier: S. 3245-3247. Vgl. zu den Ausführungen Poincarés auch den ausführlichen Bericht der deutschen Botschaft vom 18. 11. 1922 (PA-AA, R 70715).

${ }^{129}$ So etwa durch ein Mitglied einer pazifistischen Gruppe, der „Deutschen Liga für Menschenrechte (Bund Neues Vaterland)“, die den Plan wohlwollend diskutiert hatte (Brief Kuczynski an Reynaud vom 25. 11. 1922; AN, 74 AP 11). 
Ablehnung die Tatsache ausschlaggebend, daß die Grenzen seiner Bereitschaft zum Experiment mit Sachlieferungen, Industriegesprächen und anderen Alternativlösungen jenseits rein finanzpolitischer Regelungen seit dem Vertrag von Rapallo, seit den wiederholten deutschen Moratoriumsbitten vom März und Juli 1922 und insbesondere seit den gescheiterten interalliierten Reparationsgesprächen vom August 1922 erreicht waren. ${ }^{130}$ Poincaré war im Herbst 1922 aufgrund einer Vielzahl eng miteinander verwobener Gründe, wozu der starke innenpolitische Druck seitens der parlamentarischen Rechten sowie sicherheits- und finanzpolitische Gegebenheiten zählten, nicht mehr bereit, sich in eine Situation bringen zu lassen, in der er gezwungen sein konnte, seinen entschiedenen Kurs gegenüber Deutschland zu differenzieren. ${ }^{131}$ Dies zeigte sich in seiner systematischen Weigerung, die ab Herbst 1922 laufenden direkten deutsch-französischen Industrieverhandlungen durch die Entgegennahme eines deutschen Angebots zu sanktionieren. ${ }^{132}$ Auf anderer Ebene manifestierte sich diese Haltung aber auch in der unmißverständlichen Absage an Reynauds Pläne wie an dessen folgendes Angebot, in direkten Gesprächen mit Hugo Stinnes doch noch zu einer Einigung über den „Rechberg-Reynaud-Plan“ zu kommen.

\section{c) Vermittlungsgespräche in Deutschland im Frübjabr 1923}

Reynaud war entschlossen, nach den ermutigenden Erfahrungen seiner Reise vom Oktober 1922 die Vermittlertätigkeit in Unterredungen mit deutschen offiziellen Stellen wie auch mit Industriekreisen fortzusetzen. Die Gelegenheit dafür schien ihm bereits nach dem Scheitern der Konferenz von Genua außerordentlich günstig zu sein, aus deren Verlauf er Schlußfolgerungen gezogen hatte, die denen seines Regierungschefs diametral entgegenstanden. Zwar teilte er dessen zunehmen-

130 Becker/Berstein, Victoire et frustrations, S. 215. Die gravierende Verschärfung des Klimas in den deutsch-französischen Beziehungen nach Unterzeichnung des Vertrags von Rapallo analysiert insbesondere Renata Fritsch-Bournazel, Rapallo: naissance d'un mythe. La politique de la peur dans la France du Bloc national, Paris 1974, S. $168 \mathrm{ff}$.

Speziell zur sich verhärtenden Haltung Poincarés in der Frage inoffizieller Industrieverhandlungen ab Sommer 1922 vgl. auch Trachtenberg, Reparation, S. 239, der damit unter anderem ältere Thesen von der sofortigen konzeptionellen Revision der Reparationspolitik Briands nach Amtsantritt des neuen Regierungschefs widerlegt. Daß Poincaré hingegen in der Anwendung seiner Politik insbesondere im Hinblick auf eine härtere Kontrolle der deutschen Zahlungsfähigkeit sehr rasch einen schärferen Kurs einschlug, muß Trachtenberg einräumen (Ebenda, S. 237ff., hier: S. 240).

131 Vgl. zu den Motiven Poincarés am Vorabend der Ruhraktion die pertinente Analyse bei Denise Artaud, die die französische Entscheidung für die Invasion in den Gesamtzusammenhang von Reparationen, interalliierten Schulden und alliierten Plänen für ein Moratorium an Deutschland stellt. Sie rückt gegenüber älteren Interpretationen, die vorwiegend den innenpolitischen Druck auf Poincaré oder den Sicherheitsaspekt betonten, insbesondere das gescheiterte Bemühen des französischen Regierungschefs in den Vordergrund, eine im Herbst 1922 in Form eines alliierten Moratoriums für Deutschland sich abzeichnende erneute Verminderung des Reparationsertrags für Frankreich durch die Verringerung der französischen Kriegsschulden in den USA aufzufangen (Denise Artaud, A propos de l'occupation de la Ruhr, in: Revue de l'Histoire Moderne et Contemporaine 17 (1970), S. 1-21; Dies., Die Hintergründe der Ruhrbesetzung 1923. Das Problem der interalliierten Schulden, in: VfZ 27 (1979), 241-259 sowie Dies., La question des dettes interalliées et la reconstruction de l'Europe (1917-1929), Lille-Paris 1978, S. 419ff.). Der Analyse Artauds schließt sich an: Rupieper, Cuno Government, S. 86-96.

132 Vgl. hierzu Wulf, Stinnes, S. 339-341. Zur innenpolitischen Situation Poincarés: Bonnefous, Histoire III, S. 331-335. 
des Mißtrauen gegenüber den englischen Alliierten, die offenbar nicht einmal durch den Affront von Rapallo zu einer Annäherung an den französischen Standpunkt und zu härterer Kontrolle in der Reparationsfrage zu bringen waren. ${ }^{133} \mathrm{Im}$ Unterschied zu Poincaré, der nun öffentlich klarmachte, daß er im Falle neuerlicher deutscher Rückstände auch ohne englische Unterstützung zur Ruhrbesetzung schreiten würde, sah Reynaud in der englisch-französischen Entfremdung die Chance, gerade in diesem Moment, da Frankreich die Rolle des Juniorpartners der englischen Politik abgelegt habe, bilaterale Gespräche mit Deutschland anzuknüpfen: „Les Allemands ont vu la France s'affranchir de l'Angleterre à Gênes. La personne et l'attitude de M. Poincaré leur en imposent. L'heure est venue de causer avec eux. La laisserons-nous passer?" 134

So unternahm Reynaud zwischen dem 3. und 8. Januar 1923 eine neuerliche Berlinreise, in deren Verlauf er vermutlich auf Vermittlung Rechbergs mit Vertretern der Reichsbank, mit Reichsfinanzminister Hermes und mit dem Staatssekretär des Auswärtigen Amtes, von Maltzan, zusammentraf, um seine reparationspolitischen Vorstellungen zu erörtern. Die Wahl Hermes' als Gesprächspartner war kein Zufall, hatte sich dieser doch im Gefolge der Konferenz von Genua, als es für die deutsche Seite darum ging, die Feststellung eines "manquement volontaire“ durch die Reparationskommission und damit die akut drohende Ruhrbesetzung abzuwenden, als entgegenkommender Verhandlungspartner erwiesen. ${ }^{135}$ Daher lag es für Reynaud nahe, sich in der zugespitzten Situation des Januar 1923 an jenes Kabinettsmitglied zu wenden, das bereits einmal genügend Rückgrat bewiesen hatte, um selbständige Lösungswege zu vertreten. Eile tat dabei not, denn Anfang Dezember war im französischen Kabinett die Entscheidung für den Ruhreinmarsch getroffen worden, am 26. Dezember hatte die Reparationskommission ein erstes Mal deutsche Lieferrückstände konstatiert. Nun zeigte sich allerdings sehr schnell, daß man in Deutschland zu diesem Zeitpunkt kaum mehr an die Möglichkeit einer schiedlichen Lösung glaubte. So gab sich Hermes in einem Gespräch mit dem französischen Abgeordneten am 5. Januar überzeugt von der Unvermeidbarkeit der Ruhrbesetzung und erachtete den Plan Reynauds in Deutschland für nicht durchsetzbar. ${ }^{136}$ Staatssekretär von Maltzan, dem Reynaud am gleichen Tage sein bekanntes Programm vorstellte, reagierte zunächst hinhaltend. ${ }^{137}$ In einem zweiten Gespräch am 7. Januar zeigte er sich ebenfalls wenig optimistisch bezüglich des Ertrags der Reynaudschen Vorschläge wie inbesondere ihrer Akzeptanz in

133 Zur Position Poincarés nach Genua und Rapallo: Trachtenberg, Reparations, S. 243 f. Die Analyse Reynauds findet sich in: Reynaud, Et maintenant, quelle politique?

${ }^{134}$ Reynaud, Et maintenant, quelle politique? Poincaré hatte seine Entschlossenheit zum Alleingang in einer vielbeachteten Rede in Bar-le-Duc am 24. April 1922 erklärt (Trachtenberg, Reparations, S. $243 \mathrm{f}$.).

135 Eingehend zur Verhandlungsführung Hermes' und zur Kabinettskrise, die sein gegenüber der Reparationskommission gegebenes Versprechen auf eventuelle Einführung zusätzlicher Steuern zur Konsolidierung des deutschen Haushalts und als Voraussetzung für eine internationale Anleihe auslöste: Laubach, Kabinette Wirth, S. 224-236. Vgl. auch Trachtenberg, Reparations, S. 244-246.

$136 \mathrm{Vgl}$. die Gesprächsnotiz Reynauds über das Gespräch mit Hermes am 5. Januar 1923 (AN, 74 AP 11, Dossier „Voyage de Berlin. 3-8 janvier '23“)

137 Vgl. die Aufzeichnung Maltzans vom 5. 1. 1923 (Politisches Archiv des Auswärtigen Amts (künftig abgekürzt: PA-AA), R 35992; teilweise abgedruckt in: Akten zur Deutschen Auswärtigen Politik (künftig: ADAP), Serie A, Band VII, Göttingen 1989, S. 26, Anm. 1). 
Deutschland, behielt sich aber die weitere Prüfung vor. Überdies weigerte er sich strikt, angesichts der „militärischen Drohungen Poincarés“ bindende Gespräche irgendeiner Art zu führen. Reynaud hatte bereits in der Unterredung vom 5. Januar mit Kritik an Poincarés Pfänderpolitik nicht zurückgehalten und bemühte sich nun nachdrücklich, die Grenzen der deutschen Gesprächsbereitschaft und die Möglichkeiten für einen Kompromiß bei Abmilderung der Poincaréschen Lösung auszuloten. Auch als er die Möglichkeit einer Beschränkung der Ruhraktion auf die rein „administrative und nicht militärische Besetzung" oder auf die bloße Errichtung einer Zollgrenze andeutete, wurde ihm indes eine deutliche Abfuhr seitens des Staatssekretärs zuteil. Ein Gespräch mit Reichsaußenminister von Rosenberg, das Reynaud wünschte, kam nicht zustande. ${ }^{138}$

Unbeirrt von der mittlerweile vollzogenen Ruhrbesetzung versuchte Reynaud in einem zweiten Anlauf, direkten Kontakt mit der deutschen Industrie aufzunehmen, die ja Hauptbetroffene seines Vorschlages sein würde. Seit Mitte Dezember 1922 stand Rechberg in brieflichem Kontakt mit Hugo Stinnes, um diesem seine Idee der Industriebeteiligungen nahezubringen, hatte jedoch seither nicht mehr als kühle Ablehnung geerntet. Ende Januar 1923 stellte er Paul Reynaud schriftlich vor, nicht ohne allerdings dessen Einfluß in politischen und industriellen Kreisen Frankreichs stark zu übertreiben. ${ }^{139}$ Die wiederum ablehnende Reaktion Stinnes' richtete sich vor allem gegen die Vermittlung Rechbergs. Unter der Bedingung, daß die Initiative von französischer Seite käme, zeigte sich Stinnes zu Gesprächen mit „kompetente[n] französische[n] Persönlichkeiten“ durchaus bereit. ${ }^{140}$ Auf erneutes Insistieren Rechbergs hin, der in ausgesprochen zudringlicher Weise seine Bedeutung als Vermittler herauszustreichen bemüht war, wiederholte Stinnes in scharfem Ton seine Ablehnung einer Beiziehung Rechbergs ebenso wie seine prinzipielle Bereitschaft zu einem Treffen mit Reynaud. ${ }^{141}$ Dieser war nun offensichtlich entschlossen, den von Stinnes ungeliebten Mittelsmann aus dem Spiel zu halten und zudem ganz auf die Karte von Industriegesprächen zu setzen. Während er in einem bedauernden Schreiben an Rechberg Anfang März 1923 jegliche Verständigungsbasis mit der deutschen Regierung angesichts deren „selbstmörderischer Politik" verneinte und den Vorschlag öffentlicher Initiativen der französischen Politik zurückwies ${ }^{142}$, forderte er Hugo Stinnes über dessen Pariser

${ }^{138}$ Aufzeichnung des Staatssekretärs des Auswärtigen Amts Freiherr von Maltzan, 7. 1. 1923 (ADAP A VII, Dok. 12, S. 26f.).

139 So präsentierte Rechberg Reynaud als ehemaligen „Privatsekretär Millerands“ und Mitglied der Industriellenfamilie Schneider (Rechberg an Stinnes, 29.1. 1923; PA-AA, R 28189k). Vgl. hierzu und zu Reynauds Vermittlungsaktion im Frühjahr 1923 insgesamt auch Wulf, Stinnes, S. 361-369, hier: S. $361 \mathrm{f}$. Weitere Belege für Rechbergs Vorstöße bei Stinnes und im Auswärtigen Amt während des Jahres 1923 finden sich in: PA-AA, R 30184k.

1to Stinnes an Rechberg, 16. 2. 1923 (PA-AA, R 28189k).

141 „[...] Ich habe Ihnen wiederholt mitgeteilt, daß, wenn Herr Reynaud oder andere hervorragende Franzosen sich mit mir benehmen wollten, so würden sie mich zu finden wissen." (Stinnes an Rechberg, 23. 2. 1923; ADAP A VII, S. 213, Anm. 8). Vgl. auch den vorhergegangenen Brief Rechbergs an Stinnes, 19. 2. 1923; ebenda, Dok. 96, S. 211-213.

In Schreiben vom 12.1. und 1.3. 1923 hatte Stinnes den Briefwechsel mit Rechberg aus der Zeit zwischen Dezember 1922 und Februar 1923 an Außenminister von Rosenberg zur Kenntnisnahme übersandt (vgl. PA-AA, R 28189k).

142 "Je crois malheureusement que le moment n'est pas encore venu où l'intelligence pourra reprendre ses droits et où une conversation utile pourra avoir lieu. Le gouvernement allemand suit une politique de suicide qui, malheureusement, ne le concerne pas lui seul, mais aussi son pays. [...]" 
Vertreter für das Stinnes-Lubersac-Abkommen, Dr. Albert Schmidt, zu einem vertraulichen Treffen in der Schweiz auf. In engem Rahmen - Reynaud dachte für sich lediglich an die Begleitung durch Henri Lichtenberger ${ }^{143}$ - sollte frei über den Reparationsvorschlag gesprochen werden. Für den Fall einer Einigung bot Reynaud an, eine Kammermehrheit aus dem linken Flügel der radikalen Partei und Vertretern des Zentrums zu bilden, um Poincaré die gefundene Lösung entweder aufzuzwingen oder ihn zum Rücktritt zu veranlassen. Stinnes, für gewöhnlich nicht zurückhaltend, wenn es darum ging, ohne Wissen offizieller deutscher Stellen Unterredungen mit ausländischen Partnern zu führen, zögerte angesichts der Brisanz der Vorschläge nicht, Außenminister Rosenberg über das Gesprächsangebot $\mathrm{zu}$ informieren. ${ }^{144}$

Im Auswärtigen Amt begann man nun, sich verstärkt für jenen Abgeordneten zu interessieren, über dessen kritische Kammerrede vom 20. Oktober 1922 man durch die Pariser Botschaft ebenso informiert worden war wie über einen öffentlichen Vortrag an der „Ecole Interalliée des Hautes Etudes Sociales“ am 21. Februar des Folgejahrs. Hier hatte Reynaud das System der Bildung französischer Anteile an deutschem Vermögen erneut vorgetragen, ohne allerdings in der zugespitzten Situation der Ruhrbesetzung auf die Idee industrieller Kooperation zurückzukommen. ${ }^{145}$ Auf Initiative Rosenbergs prüfte man nun sowohl amtsintern wie über eine als „ganz geheim" deklarierte Rückfrage bei der Pariser Botschaft die Erfolgsaussichten der Verhandlungsoption. „Charakter, standing und Einfluß Reynauds" galt es herauszufinden, um eine fundierte Entscheidung darüber treffen zu können, ob er "das richtige Pferd“ sei. ${ }^{146}$ An der Generallinie, die man dabei einzuschlagen gewillt war, ließ von Rosenberg gegenüber Stinnes keinen Zweifel: Die Reichsregierung würde in jedem Falle abwartend im Hintergrund

(Reynaud an Rechberg, 2. 3. 1923; AN, 74 AP 11). Vgl. dazu auch bereits Reynauds Brief vom Januar (Reynaud an Rechberg, 19.1. 1923; Bundesarchiv Koblenz (BAK), NL 49, Dossier 57) und Rechbergs Anschreiben (Rechberg an Reynaud, 22. 1. 1923; AN, 74 AP 11).

Peter Wulf, dem das Schreiben Reynauds nur in der indirekten Wiedergabe einer Aufzeichnung Mutius' vorlag, in der der Adressat Rosenberg im Passus „da die deutsche Regierung in ihrer selbstmörderischen Politik verharre" den Ausdruck "deutsche Regierung" handschriftlich durch "französische Regierung" ersetzt hatte, unterstellt Reynaud hier zu Unrecht Kritik an der Regierung Poincaré. Reynaud schätzte durchaus die deutsche Politik als "selbstmörderisch“ ein (Wulf, Stinnes, S. 364. Vgl. hierzu die Aufzeichnung Mutius', 7.3. 1923; teilweise abgedruckt in: ADAP A VII, S. 298, Anm. 12).

${ }_{143}$ Der an der Sorbonne lehrende Germanist Henri Lichtenberger (1864-1941) hatte sich in seinen anerkannten Publikationen mit Sprache, Literatur, Philosophie und Geschichte Deutschlands beschäftigt, war als kühl abwägender und um Objektivität bemühter Beobachter des deutsch-französischen Verhältnisses hervorgetreten und gehörte mit Louis Bourgeois und anderen zu den ersten Verfechtern einer realistischen, nüchternen Politik der Annäherung (Siebert, Aristide Briand, S. 234). Paul Reynaud, mit dem er seit Anfang der zwanziger Jahre in regelmäßigem Meinungsaustausch stand, schätzte er als einen jener innovativen Politiker, die sich um gangbare Alternativen in der Reparationsproblematik bemühten (Henri Lichtenberger, L'Allemagne d'aujourd'hui dans ses relations avec la France, Paris 1922, S. 272; Reynaud, Mémoires I, S. 162).

$1+4$ Außenminister Rosenberg an den deutschen Geschäftsträger in Paris, von Hoesch, 4. 3. 1923 (PAAA, R 28340k).

145 Hoesch an AA, 27. 2. 1923. In der Anlage des Telegramms findet sich eine durch den Pariser Gesandtschaftsrat Martius erstellte, ausführliche Zusammenfassung des Vortrags Reynauds vom 21. 2. 1923 (PA-AA, R 28340k).

146 Rosenberg an Hoesch, 4. 3. 1923 (PA-AA, R 28340k; teilweise abgedruckt in: ADAP A VII, S. 296, Anm. 3). Vgl. auch die Aufzeichnung des Gesandten z.D. Mutius für Rosenberg, 3. 3. 1923 (PAAA, R 28340k). 
bleiben und sich auch bei einer positiven Auskunft aus Paris nicht durch öffentliches Zuraten exponieren. ${ }^{147}$ So weit kam es jedoch nicht: In einer an Reichsminister von Rosenberg persönlich adressierten, ausführlichen Nachricht übermittelte der Pariser Geschäftsträger von Hoesch schon am nächsten Tag eine präzise Einschätzung, in der sich die durchaus positive Charakteristik der Persönlichkeit des Abgeordneten mit einer überaus skeptischen Beurteilung der Erfolgschancen seines Projekts verband. Als eines der wenigen jungen Talente der Kammer, als „integer und begabt“, wenngleich auch etwas eigenbrötlerisch - so präsentierte Hoesch den Politiker, dem seine Reparationsideen zwar eine gewisse Anhängerschaft, doch keinen „[a]usschlaggebenden Einfluß" verschafft hätten. In seiner politischen Ausrichtung am linken Rand des „Bloc national“ anzusiedeln, unterhalte Reynaud auch keine nachweisbaren Verbindungen zu „besonderen Industrie- oder Bankgruppen“. So gelangte Hoesch, ohne auf den Inhalt des Reynaudschen Plans überhaupt wertend einzugehen, allein aus seiner Analyse der innenpolitischen Kräfte- und Interessenverhältnisse zu einer abratenden Einschätzung: Weder sei man in den führenden politischen Kreisen Frankreichs bereit, eine Einigung zwischen Industriellen vor einer endgültigen politischen Lösung der Ruhrfrage zuzulassen, noch müsse Poincaré zur Zeit um seine Position innerhalb des „Bloc national“ fürchten. ${ }^{148}$

Diese Beurteilung war entscheidend für die weitere Verfolgung der Angelegenheit durch das Auswärtige Amt. So stand die dilatorische Behandlung des Gesprächsersuchens bereits fest, als sich Rechberg offensichtlich ohne Kenntnis des Vorstoßes Reynauds, doch unter Verweis auf dessen Brief vom 2. März mit der Bitte um Abstimmung des weiteren Vorgehens an das Auswärtige Amt wandte. ${ }^{149}$ Inzwischen hatte nämlich der mittlerweile mit der Angelegenheit befaßte persönliche Referent Rosenbergs, Gesandtschaftsrat von Mackensen, nicht nur das Telegramm Hoeschs in gekürzter Form an Stinnes übermittelt, sondern im Auftrag des Ministers überdies eine deutliche Warnung vor dem beabsichtigten Treffen ausgesprochen. 150

Weniger die Vorbehalte des Außenamts als vielmehr die Tatsache, daß Reynaud seinen vorgesehenen Gesprächspartner Hugo Stinnes in Paris als den eigentlich an einer Begegnung Interessierten darstellte, ließen die Annäherungsbemühungen kurzzeitig in Gefahr geraten. Prinzipiell blieb Stinnes nach wie vor bereit zu einem Treffen, für das er gegebenenfalls seine Essener Privatwohnung zur Verfügung stellen wollte. ${ }^{151}$ Eine für den 16. März vereinbarte Zusammenkunft in Wiesbaden scheiterte dann aber am Veto der französischen Regierung und an der Wei-

${ }_{147}$ Aufzeichnung Rosenbergs, 4. 3. 1923 (PA-AA, R 28340k; teilweise abgedruckt in: ADAP A VII, S. 298, Anm. 9).

148 Hoesch an Rosenberg, 5. 3. 1923 (ADAP A VII, Dok. 123, S. 296-298).

149 Vgl. die Aufzeichnung Mutius' für Rosenberg vom 7.3. 1923 über ein Gespräch mit Rechberg vom gleichen Tag (PA-AA, R 28340k; teilweise abgedruckt in: ADAP A VII, S. 298, Anm. 12).

$150 \mathrm{Vgl}$. hierzu die handschriftlichen und auf den 5.3. bzw. 6.3. 1923 datierten Bemerkungen von Mackensens auf der um die Namen der Beteiligten gekürzten Fassung der Depesche Hoeschs (PAAA, R 28340k).

151 Aufzeichnung Rosenbergs über ein Gespräch mit Reichswirtschaftsminister Becker und Hugo Stinnes, 18. 3. 1923 (PA-AA, R 28189k). Anders als Wulf aus diesem Dokument entnimmt, fand die Gesprächsbereitschaft beider Seiten somit zu diesem Zeitpunkt noch keineswegs ihr Ende (Wulf, Stinnes, S. 364). 
gerung der Behörden, Reynaud auf deutsches Territorium einreisen zu lassen.152 In einem Gespräch mit Poincaré tags darauf unterwarf sich Reynaud dieser Entscheidung, nicht ohne jedoch gegenüber seinem skeptischen Ministerpräsidenten weiterhin auf den Vorteilen inoffizieller bilateraler Gespräche zu beharren.153 Dessen Abneigung gegen Unterredungen dieser Art verhinderte im Verlauf des Jahres 1923 eine Folge weiterer Vorstösse Reynauds, die darauf abzielten, mit offizieller Billigung doch noch in Verbindung zu deutschen Gesprächspartnern zu treten. Ein über Henri Lichtenberger Ende April unter geradezu konspirativen Umständen anvisiertes Treffen mit Stinnes stieß ebenso auf die Ablehnung Poincarés ${ }^{154}$ wie ein erneuter Versuch im Juni155 oder Pläne für ein Treffen mit Stresemann, das Rechberg - unter klarer Überschreitung seiner Kompetenzen - im August und September in Aussicht stellte. ${ }^{156}$

Der offensichtliche Mißerfolg seiner Bemühungen ließ Reynaud nun vorläufig von einer weiteren Verfolgung seiner Ideen Abstand nehmen. Über fast drei Jahre hinweg hatte er versucht, Alternativmodelle für eine die Interessenlage von Siegern und Besiegten gleichermaßen einbeziehende Reparationslösung mehrheitsfähig zu machen, was ihm weder auf parlamentarischer Ebene noch über den Weg direkter inoffizieller Gespräche gelungen war. Zwar konnte er als Bestätigung seines Vorstoßes verstehen, daß es in unmittelbarem zeitlichem Anschluß an die thematisch gleichgerichteten Parlamentsdebatten vom Mai 1921, die er mitgeprägt hatte, zur Einleitung deutsch-französischer Sachlieferungsgespräche gekommen war. Die Schwierigkeiten, das Wiesbadener Abkommen in die Tat umzusetzen, zeigten aber auch ihm, wie hart sich die Positionen im Raume stießen, wenn es galt, die praktische Umsetzung selbst vielversprechender Ansätze zu erreichen. Nachdem das deutsche Moratoriumsgesuch den offensichtlichen Fehlschlag auch des Sachlieferungskonzepts signalisierte, hatte er sich einer Alternative zuge-

${ }_{152}$ Am 15. März hatte Poincaré den französischen Hochkommissar im Rheinland, Tirard, davon in Kenntnis gesetzt, daß er kein Treffen zwischen Stinnes und Reynaud wünsche (Rupieper, Cuno Government, S. 144).

153 Seinen eigenen Notizen zufolge hielt Reynaud Poincaré u.a. entgegen: „Je lui dis si vous attendez que le gouv[ernemen]t all[eman]d v[ou]s d[eman]de officiel[lemen]t de causer, il y aura l'Anglais, l'Italien, l'Américain, v[ou]s retombez d[an]s la polit[ique] des conférences et v[ou]s perdez le bénéfice de l'opération faite par nos seuls efforts \& dont nous courons tous les risques." (Handschriftliche Aufzeichnung Reynauds über ein Gespräch mit Poincaré, 17.3. 1923; AN, 74 AP 11).

154 Peretti de la Rocca, der Leiter der politischen Abteilung im Außenministerium, teilte Reynaud Anfang Mai 1923 im Auftrag Poincarés telephonisch sinngemäß mit: „Le P[résiden]t du Conseil $\mathrm{v}[\mathrm{ou}] \mathrm{s}$ laisse libre mais il n'approuve pas; il trouve que c'est inutile et dangereux “(Handschriftliche Gesprächsnotiz Reynauds vom 3. 5. 1923; AN, 74 AP 11). Zuvor hatte Reynaud in einem Brief an den Ministerpräsidenten erneut sein Interesse an Sondierungen in „qualifizierten deutschen Kreisen " bekundet, hatte eine Note Stinnes' zur Reparationsfrage in Aussicht gestellt und Poincarés Einverständnis für sein Vorgehen erbeten (Reynaud an Poincaré, 27. 4. 1923; AN, 74 AP 11).

155 Vgl. dazu Wulf, Stinnes, S. 364, Anm. 93 sowie Reynaud, Mémoires I, S. 170 f.

156 Vgl. hierzu die Briefe Rechbergs an Reynaud vom 14.8. und 5. 9. 1923, die Anschreiben Reynauds an Poincaré vom 27.8. und 16.9. sowie die Antwort Poincarés, in der dieser Reynaud lediglich autorisierte, für den Fall der Beendigung des passiven Widerstands die Gesprächsbereitschaft der französischen Regierung zu signalisieren: „[...] Je vois le plus grand inconvénient à ces pourparlers indirects, qui ne peuvent amener qu'obscurité et contradiction." (Poincaré an Reynaud, 21.9. 1923; zitiert nach: Reynaud, Mémoires I, S. 172 f., hier: S. 173. Die genannten Briefe finden sich, obwohl in seinen Memoiren erwähnt und in Auszügen wiedergegeben, nicht im Nachlaß Reynauds). Vgl. dazu auch die Briefe Reynauds an Rechberg vom 9.5. und 27.8. 1923 (BAK, NL 49, Dossier 57). 
wandt, die die Stärken des alten Vorschlags - die Umgehung des Transferproblems unter Befriedigung der Interessen beider Seiten und die Option auf weiterreichende Zusammenarbeit - vergeblich mit den Präferenzen Poincarés in Einklang zu bringen versuchte. Hatte er bislang nicht davor zurückgescheut, seine Ideen gegen die weitgehend schweigende eigene parlamentarische Mehrheit vorzutragen und unpopuläre Lösungen vorzuschlagen, so ging er im Frühjahr 1923, enttäuscht von der Reparationspolitik Poincarés, bis hart an die Grenze der Illoyalität gegenüber seinem Regierungschef. Seine Gesprächsversuche kurz vor und während der Ruhrbesetzung scheiterten weder an selbstauferlegter Zurückhaltung noch am Desinteresse seines Verhandlungspartners Hugo Stinnes. Sie scheiterten vorwiegend an der Gesprächsunwilligkeit beider Regierungen, die Anfang Januar 1923 bereits zum passiven Widerstand bzw. zur Härte entschlossen waren, sowie nicht zuletzt an seinem eher begrenzten parlamentarischen Einfluß, der ihn auf deutscher Seite als zu wenig potenten Mittler erscheinen ließ. Ein versuchter Sturz Poincarés hätte, falls die Angaben der deutschen Berichterstatter in diesem Punkt der Wahrheit entsprechen, für den an parlamentarischen Jahren noch jungen $\mathrm{Ab}$ geordneten ein durchaus gewagtes Unterfangen bedeutet. Wahrscheinlich ist, daß eine derartige Absichtserklärung gerade den fehlenden starken Rückhalt suggerieren sollte. Im Mai 1921 war Reynaud Teil und Träger einer ad hoc sich unter dem gemeinsamen Nenner der Sachlieferungslösung zusammenfindenden Interessenskoalition gewesen. Die Idee der Übernahme von deutschen Industrieanteilen besaß diese Zugkraft nicht mehr: In der Debatte vom 22. Oktober 1922 machte Reynaud nicht einmal mehr den Versuch, einen entsprechenden Entschließungsantrag einzubringen.

Am Ende der 12. Legislaturperiode der französischen Kammer konnte die persönliche Bilanz Reynauds dennoch positiv ausfallen. Zusammen mit Pierre Forgeot hatte er als einer der ersten Abgeordneten der "modérés“ die Idee der wirtschaftlichen Annäherung an Deutschland der starren Zwangspolitik entgegengesetzt. $\mathrm{Zu}$ unabhängig in seinem Urteil, um sich mit mehrheitlich vertretenen Lösungen zufriedenzugeben, genügend selbstbewußt, um Alternativen präzise zu formulieren und den Versuch zu unternehmen, sie in die Tat umzusetzen, hatte er die Spitzen der Vorkriegsgeneration französischer Politiker, Briand und Poincaré, herausgefordert und war in die Schranken seiner noch beschränkten politischen Wirksamkeit gewiesen worden. Seit seinen allzu nahe an sozialistischen Lösungsmodellen liegenden und in politiknahen Unternehmerkreisen ausgesprochen unpopulären Reparationsvorschlägen beobachtete ihn der tragende rechte Flügel der eigenen Mehrheit mit abwartender Skepsis, ohne daß er von der Linken dagegen erkennbar als willkommener Bundesgenosse akzeptiert worden wäre. Auch waren seine deutschlandpolitischen parlamentarischen Aktivitäten nicht im parteipolitischen Rahmen vor sich gegangen. Er hatte im Mai 1921 ohne Parteimandat im Namen einer kleinen Gruppe von Abgeordneten gesprochen, die verschiedenen Parteien bzw. Fraktionen der Mitte und der Rechten entstammten. ${ }^{157}$ Konzeptionell standen seine Bemühungen um den rational fundierten Ausgleich mit

157 Georges Bonnefous etwa gehörte wie Edouard de Warren, Pierre Taittinger und Edouard Soulier der "Fédération Républicaine" an, Charles Reibel war Mitglied der "Alliance“; vgl. Kapitel V.2.a). 
Deutschland geradezu im Gegensatz zu den offiziellen Äußerungen der „Alliance Républicaine Démocratique“. Dort favorisierte man - ohne wirklich klare Programmatik in der Reparationsfrage - bereits im Mai 1921 die Besetzung der Ruhr und die Politik der Einforderung von Faustpfändern, lehnte die These von der beschränkten deutschen Zahlungsfähigkeit ab und stand Sachlieferungen nur vorsichtig abwartend gegenüber.158

Rhetorische Brillanz, scharfes Differenzierungsvermögen und die Lust am sachbezogenen Meinungsstreit hatten Reynaud als Persönlichkeit, nicht als Parteipolitiker Achtung in der politischen Klasse und die regelmäßige Aufmerksamkeit der Kammer erworben. 159 Über den Rahmen eines engagierten und in außenund finanzpolitischen Fragen überdurchschnittlich sachkundigen Abgeordneten war er jedoch noch nicht hinausgetreten. Allzuwenig hatten dazu die Kammerauftritte während der hochspezialisierten Reparationsdiskussionen wirklich greifbare Ergebnisse gezeitigt oder den Nerv des öffentlichen Interesses berührt.

Bekanntheit bei politischen Beobachtern auf nationaler Ebene und Gewicht als ein Sprecher und potentieller Führer der rechten Mitte erlangte Reynaud im $\mathrm{Zu}$ sammenhang spektakulärerer politischer Kraftproben, vor allem nach den allgemein mit Aufmerksamkeit betrachteten Nachwahlen in Paris vom März 1926.

158 Vgl. die Stellungnahmen in der Parteipresse: „D'abord saisir un gage, causer après“, in: La République Démocratique, 1. 5. 1921; „Avant le débat sur les accords de Londres“, ebenda, 15. 5. 1921; "Les solutions pratiques“, ebenda, 29. 5.1921.

159 Es sei daran erinnert, daß etwa Poincaré es als nötig erachtete, auf die Reparationsvorschläge Reynauds in ausführlichen Einlassungen zu reagieren (JO, Chambre des Députés, $2^{c}$ Séance du 17 novembre 1922, S. 3245-3247). 